\title{
Cornichon-2 Modulates AMPA Receptor-Transmembrane AMPA Receptor Regulatory Protein Assembly to Dictate Gating and Pharmacology
}

\author{
Martin B. Gill, ${ }^{1 \star}$ Akihiko S. Kato, ${ }^{1 \star}$ Matthew F. Roberts, ${ }^{2}$ Hong Yu, ${ }^{1}$ He Wang, ${ }^{1}$ Susumu Tomita, ${ }^{2}$ and David S. Bredt ${ }^{1}$ \\ ${ }^{1}$ Neuroscience Discovery Research, Eli Lilly and Company, Indianapolis, Indiana 46285, and ${ }^{2}$ Department of Cellular and Molecular Physiology, Program in \\ Cellular Neuroscience, Neurodegeneration and Repair, Yale University School of Medicine, New Haven, Connecticut 06510
}

\begin{abstract}
Neuronal AMPA receptor complexes comprise a tetramer of GluA pore-forming subunits as well as accessory components, including transmembrane AMPA receptor regulatory proteins (TARPs) and cornichon-2/3 (CNIH-2/3). The mechanisms that control AMPA receptor complex assembly remain unclear. AMPA receptor responses in neurons differ from those in cell lines transfected with GluA plus TARPs $\gamma-8$ or $\gamma-7$, which show unusual resensitization kinetics and non-native AMPA receptor pharmacologies. Using tandem GluA/ TARP constructs to constrain stoichiometry, we show here that these peculiar kinetic and pharmacological signatures occur in channels with four TARP subunits per complex. Reducing the number of TARPs per complex produces AMPA receptors with neuron-like kinetics and pharmacologies, suggesting a neuronal mechanism controls GluA/TARP assembly. Importantly, we find that coexpression of CNIH-2 with GluA/TARP complexes reduces TARP stoichiometry within AMPA receptors. In both rat and mouse hippocampal neurons, $\mathrm{CNIH}-2$ also associates with AMPA receptors on the neuronal surface in a $\gamma$-8-dependent manner to dictate receptor pharmacology. In the cerebellum, however, CNIH-2 expressed in Purkinje neurons does not reach the neuronal surface. In concordance, stargazer Purkinje neurons, which express CNIH-2 and $\gamma-7$, display AMPA receptor kinetics/pharmacologies that can only be recapitulated recombinantly by a low $\gamma$-7/GluA stoichiometry. Together, these data suggest that CNIH-2 modulates neuronal AMPA receptor auxiliary subunit assembly by regulating the number of TARPs within an AMPA receptor complex to modulate receptor gating and pharmacology.
\end{abstract}

\section{Introduction}

Ionotropic AMPA receptors, key components of excitatory CNS neurotransmission, comprise a heterotetramer of principal, channel-forming subunits (GluA1-4), which are alternatively spliced and assembled as dimer-of-dimers (Seeburg, 1993; Hollmann and Heinemann, 1994; Dingledine et al., 1999; Mayer and Armstrong, 2004; Collingridge et al., 2009; Sobolevsky et al., 2009). Most, if not all, neuronal AMPA receptor complexes also contain transmembrane AMPA receptor regulatory proteins (TARPs). Studies have identified six TARP isoforms, classified into type I ( $\gamma-2,-3,-4$, and -8$)$ and type II ( $\gamma-5$ and -7$)$ subfamilies, which differentially modulate synaptic trafficking and gating of neuronal AMPA receptors throughout the brain (Moss et al., 2003; Tomita et al., 2003; Fukaya et al., 2005; Cho et al., 2007; Kato et al., 2007, 2008; Milstein et al., 2007; Soto et al., 2009).

Received Nov. 30, 2010; revised Feb. 7, 2011; accepted March 18, 2011.

Author contributions: M.B.G., A.S.K., S.T., and D.S.B. designed research; M.B.G., A.S.K., M.F.R., and H.Y. performed research; H.W. contributed unpublished reagents/analytic tools; M.B.G., A.S.K., M.F.R., H.Y., S.T., and D.S.B. analyzed data; M.B.G., A.S.K., S.T., and D.S.B. wrote the paper.

This work was supported in part by National Institute of Mental Health Grant R01 MH077939 (S.T.).

M.B.G., A.S.K., H.Y., H.W., and D.S.B. are full-time employees of Eli Lilly and Company.

*M.B.G. and A.S.K. contributed equally to this work.

Correspondence should be addressed to either Akihiko S. Kato or David S. Bredt, Lilly Research Laboratories, Eli

Lilly and Company, Indianapolis, IN 46285-0510. E-mail: katoak@lilly.com or dbredt@gmail.com.

DOI:10.1523/JNEUROSCI.6271-10.2011

Copyright $\odot 2011$ the authors $\quad 0270-6474 / 11 / 316928-11 \$ 15.00 / 0$
The mechanisms controlling TARP assembly into AMPA receptor complexes remain unclear. In $\gamma$-8-containing hippocampal neurons, TARP stoichiometry is either two or four per AMPA receptor complex dependent on neuronal subtype (Shi et al., 2009). Another study found that $\gamma-2$ stoichiometry is fixed at one per AMPA receptor complex in cerebellar granule neurons (Kim et al., 2010). Because TARPs dose-dependently modulate AMPA receptor gating (Milstein et al., 2007), understanding mechanisms that control TARP stoichiometry within AMPA receptors is crucial.

Proteomic analyses have identified additional AMPA receptor accessory proteins. In particular, cornichon $2 / 3(\mathrm{CNIH}-2 / 3)$ promotes surface trafficking and enhance gating of recombinant AMPA receptors (Schwenk et al., 2009). Recent studies found that overexpressed $\mathrm{CNIH}-2$ cannot reach the neuronal surface in transfected cerebellar granule cells and only promotes Golgi trafficking of AMPA receptors (Shi et al., 2010). Others studies showed that endogenous hippocampal CNIH-2 localizes in part to the neuronal surface and acts synergistically with $\gamma-8$ to regulate AMPA receptor pharmacology and gating (Kato et al., 2010). The distinct conclusions between these studies may reflect that the first primarily focused on CNIH-2 effects in cerebellar preparations, which predominantly express TARPs $\gamma-2$ and $\gamma-7$, whereas the second analyzed the effects of CNIH-2 on $\gamma-8$ containing hippocampal AMPA receptors. The latter study also showed that coexpression of GluA subunits with $\gamma-4,-7$, and -8 produces channels with unique resensitization kinetics not seen 
in native neurons and that $\mathrm{CNIH}-2$ blunts this resensitization (Kato et al., 2010).

Using tandem GluA-TARP constructs to constrain stoichiometry (Shi et al., 2009), we find that resensitization is a feature of certain four-TARP- but not two-TARP-containing AMPA receptors. We observed that $\mathrm{CNIH}-2$ blocks resensitization via reducing the number of TARPs per AMPA receptor complex. The pharmacological properties of hippocampal AMPA receptors reflect the presence of both $\gamma-8$ and CNIH-2, and surface expression of $\mathrm{CNIH}-2$ requires $\gamma-8$. By contrast, $\mathrm{CNIH}-2$ in the cerebellum is not present on the cell surface. Purkinje neurons from stargazer mice, which contain $\gamma-7$ and CNIH-2 but not $\gamma-2$, express AMPA receptor complexes that show electrophysiological properties resembling low $\gamma-7$ stoichiometry AMPA receptors without CNIH-2. Thus, CNIH-2 can modulate the stoichiometry of multiple TARP isoforms but only associates at the cell surface with specific TARP-containing AMPA receptors.

\section{Materials and Methods}

Materials. All salts, precast gels, and buffers were purchased from SigmaAldrich, Invitrogen, Thermo Fisher Scientific, or Bio-Rad. Antagonists and agonists were purchased from Tocris Bioscience. Polyclonal antibodies against pan-type I TARP (07-577) and GluA1 (AB1504) and monoclonal antibody against GluA2 (MAB3397) were purchased from Millipore. Mouse monoclonal TUJ1 antibody (MM5-435P) was purchased from Covance. Mouse monoclonal synaptophysin antibody (S5768) was purchased from Sigma-Aldrich. Affinity-purified guinea pig and rabbit polyclonal antibodies for CNIH-2, $\gamma-8, \gamma-7$, and $\gamma$-2 were generated as described previously (Kato et al., 2010; Kim et al., 2010). HRP-conjugated anti-guinea pig secondary antibody (706-035-148) and HRP-conjugated native secondary antibody for mouse- and rabbitderived primary antibodies (21230) were from Jackson ImmunoResearch Laboratories and Thermo Fisher Scientific, respectively.

Animal housing and care. Adult male Wistar rats were obtained from Charles River Laboratories. Stargazer male mice and littermate male C57BL/6 controls were obtained from The Jackson Laboratory. Animals were housed under $12 \mathrm{~h}$ light/dark cycles with access to food and water $a d$ libitum until they were killed for study following protocols approved by Eli Lilly and Company Internal Animal Care and Use Committee.

cDNA cloning and tandem construct generation. All GluA cDNAs are flip splice variants unless indicated. GluAlo refers to the flop splice variant of the GluA1 isoform. All GluA and TARP cDNAs were derived from human except for GluA2, which was cloned from rat. Tandem constructs were generated by directly linking the $\mathrm{N}$ terminus of the TARP protein to the C-terminal tail of the GluA subunit. No amino acid linker was placed in between the GluA and TARP encoding cDNAs.

Recombinant cell culture and transfection. HEK $293 \mathrm{~T}$ cells were maintained at $37^{\circ} \mathrm{C}$ in $5 \% \mathrm{CO}_{2}$ high-glucose DMEM medium supplemented with $10 \%$ fetal calf serum and $1 \%$ penicillin-streptomycin and split biweekly or triweekly. HEK 293T cells were plated in $35 \mathrm{~mm}$ dishes and were transiently transfected using FuGENE 6 according to manufacturer's protocols (11814443001: Roche Applied Science). GluA, TARP, and CNIH cDNAs were cotransfected with a green fluorescent protein (GFP)-expressing reporter plasmid for identification in electrophysiology experiments. Experiments were performed $48-72 \mathrm{~h}$ after transfection.

Native gel experiments from oocyte and hippocampal protein. Oocytes were harvested and maintained as described previously (Kim et al., 2010). Blue native PAGE (BN-PAGE) was conducted as previously described (Vandenberghe et al., 2005; Kim et al., 2010).

Acutely isolated neurons. Hippocampal pyramidal and cerebellar Purkinje neurons from five \pm 3 -month-old mice were isolated as previously described (Kato et al., 2008). Briefly, a rapidly dissected brain was immersed in ice-cold $\mathrm{NaHCO}_{3}$-buffered saline solution (in mM: $120 \mathrm{NaCl}$, $2.5 \mathrm{KCl}, 1 \mathrm{MgCl}_{2}, 1.25 \mathrm{Na}_{2} \mathrm{PO}_{4}, 2 \mathrm{CaCl}_{2}, 26 \mathrm{NaHCO}_{3}$, and 10 glucose, $\mathrm{pH}$ 7.2; osmolarity, $300 \pm 2 \mathrm{mOsm} / \mathrm{L}$ ). Coronal hippocampal and cerebellar slices (400 $\mu \mathrm{m}$ thick) were prepared by a Vibroslice (Campden Instruments) in ice-cold $\mathrm{NaHCO}_{3}$-buffered saline solution and then were re- covered at room temperature in continuously oxygenated $\left(95 \% \mathrm{O}_{2}, 5 \%\right.$ $\mathrm{CO}_{2}$ ), $\mathrm{NaHCO}_{3}$-buffered saline solution for $0.5-5 \mathrm{~h}$. The slices were transferred to a solution containing low- $\mathrm{Ca}^{2+}$ HEPES-buffered saline (low-Ca ${ }^{2+} \mathrm{HBS}$ ) (in mM: 140 sodium isothionate, $2 \mathrm{KCl}, 4 \mathrm{MgCl}_{2}, 0.1$ $\mathrm{CaCl}_{2}$, 15 HEPES, pH 7.2; osmolarity, $300 \pm 2 \mathrm{mOsm} / \mathrm{L}$ ). Dissected hippocampal CA1 regions and cerebella were placed into protease type XIV (1 mg/ml; Sigma-Aldrich) dissolved in oxygenated HEPES-buffered HBSS (HBSS 6136; Sigma-Aldrich) and maintained at $37^{\circ} \mathrm{C}, \mathrm{pH} 7.4$, osmolarity, $300 \pm 5 \mathrm{mOsm} / \mathrm{L}$. After $30 \mathrm{~min}$ incubation, the tissue was rinsed three times with the low- $\mathrm{Ca}^{2+} \mathrm{HBS}$ and triturated using firepolished Pasteur pipettes. Hippocampal pyramidal and cerebellar Purkinje neurons were selected on the basis of their characteristic morphology.

Electrophysiology. Agonist-evoked currents were recorded from transfected HEK 293T cells and acutely isolated neurons as described previously (Kato et al., 2008). Recordings were made using thick-walled borosilicate glass electrodes pulled and fire-polished to a resistance of 2-5 $\mathrm{M} \Omega$. All cells were voltage clamped at $-80 \mathrm{mV}$, and data were collected and digitized using Axoclamp 200 and Axopatch software and hardware (Molecular Devices). For whole-cell recordings, the transfected HEK $293 \mathrm{~T}$ cells were bathed in external solution containing the following [in mM: 117 tetraethylammonium (TEA), $13 \mathrm{NaCl}, 5 \mathrm{BaCl}_{2}, 1 \mathrm{MgCl}_{2}, 20$ $\mathrm{CsCl}, 5$ glucose, and $10 \mathrm{Na}-\mathrm{HEPES}, \mathrm{pH} 7.4 \pm 0.03]$. For acutely isolated neurons, $10 \mu \mathrm{M}$ CPP (3-[( \pm )-2-carboxypiperazin-4-yl]-propyl-1-phosphonic acid), $10 \mu \mathrm{M}$ bicuculline, and $1 \mu \mathrm{M}$ TTX were added to the external solution and the extracellular concentration of $\mathrm{NaCl}$ was increased to $130 \mathrm{~mm}$ and TEA was omitted. The intracellular electrode solution contained the following (in mM): $160 \mathrm{~N}$-methyl-D-glucamine, $4 \mathrm{MgCl}_{2}, 40.0$ Na-HEPES, pH 7.4, 12 phosphocreatine, $2.0 \mathrm{Na}_{2}$-ATP, pH $7.2 \pm 0.02$ adjusted by $\mathrm{H}_{2} \mathrm{SO}_{4}$. For experiments involving measurement of currentvoltage ratios, we used the following internal solution (in $\mathrm{mM}$ ): $130 \mathrm{CsCl}$, $2.5 \mathrm{MgCl}_{2}, 1$ EGTA, 10 HEPES, $0.5 \mathrm{CaCl}_{2}, 12$ phosphocreatine, $4 \mathrm{Mg}$ ATP, pH $7.2 \pm 0.02$ adjusted with $\mathrm{CsOH}$. The transfected HEK 293T cell or the acutely isolated neuron was lifted and perfused with ligandcontaining solutions from a 16-barrel glass capillary pipette array positioned 100-200 $\mu \mathrm{m}$ from the cells (VitroCom). Agonists (1 mM) were applied as indicated. Potentiation experiments were carried in cells preincubated for $1 \mathrm{~min}$ with cyclothiazide (CTZ) $(200 \mu \mathrm{M})$. Resensitization percentage was calculated as follows: $I_{\text {Glu-Resens }} / I_{\text {Glu-Des }} \times 100$, where $I_{\text {Glu-Resens }}$ is the current that accrues from the trough of desensitization (see Fig. $1 A$ ). Kainate $(\mathrm{KA}) /$ glutamate ratios were calculated as follows: $I_{\mathrm{KA}} / I_{\mathrm{Glu}}$, where $I_{\mathrm{KA}}$ and $I_{\mathrm{Glu}}$ are the steady-state responses evoked by kainate and glutamate application, respectively. CTZ potentiation of kainate-evoked responses was calculated as follows: $\left(\left(I_{\mathrm{KA}+\mathrm{CTZ}} / I_{\mathrm{KA}}\right) \times\right.$ $100)-100$, where $I_{\mathrm{KA}+\mathrm{CTZ}}$ is the steady-state current amplitude recorded during kainate plus CTZ application and $I_{\mathrm{KA}}$ is the steady-state current amplitude recorded during kainate application. Potentiation of glutamate by cyclothiazide was expressed as a fold relative to the glutamate-evoked current alone as follows: $I_{\mathrm{Glu}+\mathrm{CTZ}} / I_{\mathrm{Glu}}$, where $I_{\mathrm{Glu}+\mathrm{CTZ}}$ is the steady-state current amplitude recorded during glutamate plus CTZ application and $I_{\mathrm{Glu}}$ is the steady-state current amplitude recorded during glutamate application. Analyses were performed using Clampfit software (Molecular Devices).

Slice biotinylation. Slice biotinylation was performed essentially as described previously (Kato et al., 2010). Four hundred micrometer mouse hippocampal and stargazer mouse cerebellar slices were incubated in slicing buffer (in mм: $124 \mathrm{NaCl}, 26 \mathrm{~mm} \mathrm{NaHCO}, 3 \mathrm{KCl}, 10$ glucose, 0.5 $\mathrm{CaCl}_{2}$, and $4 \mathrm{MgCl}_{2}$ ) for $30 \mathrm{~min}$ and then recovered in biotinylation solution for $30 \mathrm{~min}$ at room temperature (biotinylation solution is slicing solution except $\left[\mathrm{CaCl}_{2}\right]$ and $\left[\mathrm{MgCl}_{2}\right]$ were raised to 2.3 and $1.3 \mathrm{~mm}$, respectively). Slices were then preincubated in ice-cold biotinylation solution for $\sim 1 \mathrm{~min}$. Surface proteins of the dissected tissue were labeled with sulfo-NHS-SS-biotin $(1.5 \mathrm{mg} / \mathrm{ml}$; Pierce) for $30 \mathrm{~min}$ on ice and the reaction quenched with glycine $(50 \mathrm{mM})$. Hippocampi and cerebella were homogenized with Tris buffer (TB) (50 mm Tris, pH 7.4, 2 mм EGTA) and then sonicated. To isolate membrane the fraction, homogenates were centrifuged at $100,000 \times g$ for $20 \mathrm{~min}$, and the pellet was resuspended in $\mathrm{TB}$ containing $\mathrm{NaCl}$ (TN) (TB plus $100 \mathrm{~mm} \mathrm{NaCl}$ ). The membrane was solubilized with $0.4 \%$ SDS in TN for $5 \mathrm{~min}$ at $4^{\circ} \mathrm{C}$ and then 

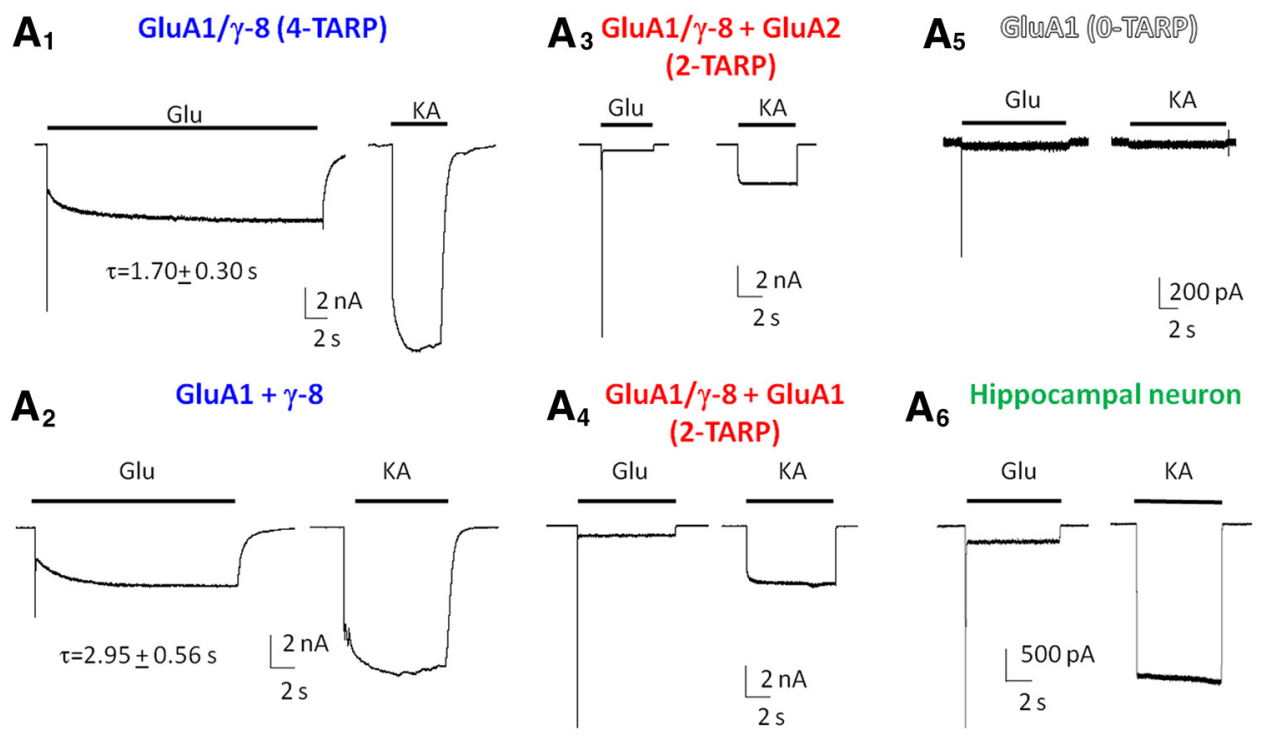

A5 GRIAS (0-TARPP)

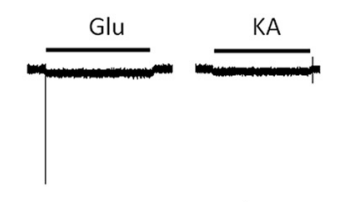

$200 \mathrm{pA}$

$2 \mathrm{~s}$
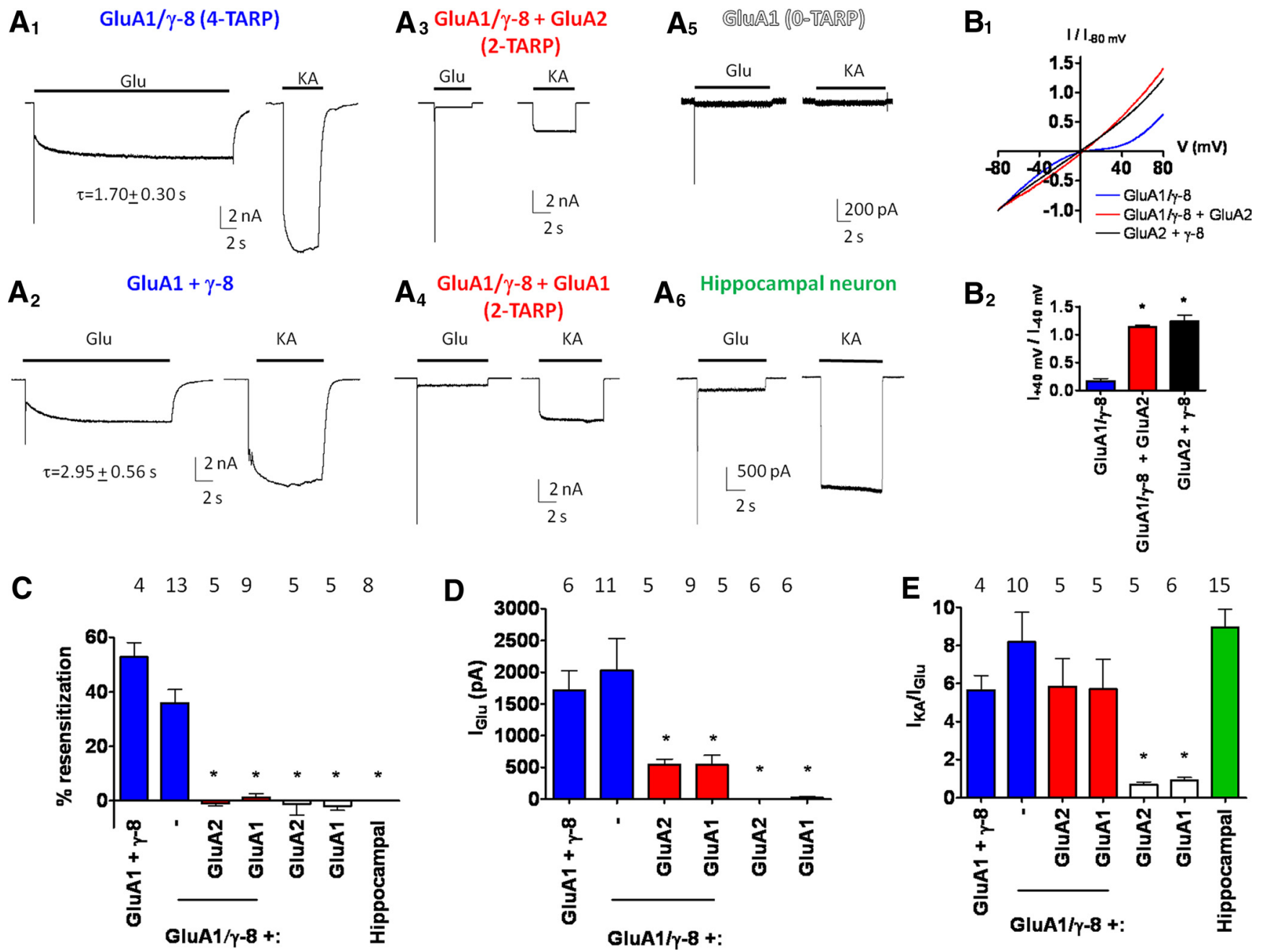

Figure 1. The number of $\gamma-8$ subunits per AMPA receptor regulates resensitization. $A$, Representative traces of kainate- and glutamate-evoked currents from $H E K 293 T$ cells cotransfected with tandem GluA1/ $\gamma-8\left(\boldsymbol{A}_{1} ;\right.$ four TARPs), nontethered GluA1 plus $\gamma-8\left(\boldsymbol{A}_{2}\right)$, GluA1/ $\gamma$-8 plus GluA2 $\left(\boldsymbol{A}_{3} ;\right.$ two TARPs), GluA1/ $\gamma$-8 plus GluA1 ( $\boldsymbol{A}_{4} ;$ two TARPs), GluA1 ( $\left.\boldsymbol{A}_{5}\right)$, or from acutely isolated CA1 hippocampal neurons $\left(\boldsymbol{A}_{\mathbf{6}}\right) . \boldsymbol{B}_{1}, \boldsymbol{B}_{2}$, Linear rectification confirms incorporation of nontethered GluA2 subunit within GluA1/ $\gamma$-8-containing AMPA receptor complexes. $\boldsymbol{C}$, Quantification reveals that only four-TARP $\gamma$-8-containing AMPA receptors exhibit resensitization. $\boldsymbol{D}$, Reducing the number of $\gamma$ - 8 subunits per AMPA receptor complex decreases the magnitude of glutamate-evoked steady-state current. $\boldsymbol{E}$, Reducing the number of $\gamma$-8 subunits per AMPA receptor complex does not alter the TARP-dependent high kainate to glutamate current ratio. ${ }^{*} p<0.05$ when compared with GluA1/ $\gamma-8(\boldsymbol{B})$ or GluA1 plus $\gamma-8(\boldsymbol{C}-\boldsymbol{E})$. Numbers of repetitions are indicated above the bar graphs. Summary data are mean \pm SEM.

neutralized with 10 -fold excess of Triton X-100. The lysate was cleared by spinning at $100,000 \times g$ for 20 min. Twenty microliters of ULTRA link Neutravidin resin (Roche) was added and incubated at $4^{\circ} \mathrm{C}$ for $2 \mathrm{~h}$. Nonbound internal protein solution was removed. Beads were washed with radioimmunoprecipitation assay buffer and biotinylated surface proteins were eluted by boiling for $5 \mathrm{~min}$ in Laemmli buffer containing DTT $(7.7 \mathrm{mg} / \mathrm{ml})$. Eluted proteins and internal proteins were separated by SDS-PAGE and detected via Western blotting.

Statistics. Data are represented as mean \pm SEM and are the result of at least three independent experiments. Analyses involving three or more data sets were performed with a one-way ANOVA with a Tukey-Kramer post hoc analysis, unless otherwise indicated, using GraphPad Prism software. Analyses involving two data sets were performed with an uncorrected Student $t$ test or with a Student $t$ test with a Welsh correction, only if the variances were statistically different. Significance was set as a value of $p<0.05$.

\section{Results}

AMPA receptors containing two $\gamma-8$ subunits per AMPA receptor complex do not exhibit resensitization

We recently found that cotransfection of GluA subunits with $\gamma-4$, $\gamma-7$, or $\gamma-8$ yields receptors that display glutamate-evoked "resensitization," which involves slow accrual of steady-state current after desensitization (Kato et al., 2010). AMPA receptors in hippocampal neurons contain $\gamma-8$ but show no resensitization. To understand better the mechanism for TARP-induced resensitization, we evaluated the effect of TARP stoichiometry. To express receptors with four TARPs per AMPA receptor complex, we used a previously described strategy and generated a GluA1/ $\gamma-8$ tandem construct that has the $\mathrm{N}$ terminus of $\gamma-8$ covalently tethered to the C terminus of GluA1 (Morimoto-Tomita et al., 2009; Shi et al., 2009). We found that glutamate-evoked currents from the GluA1/ $\gamma-8$ tandem construct (four TARPs) qualitatively reproduced the resensitization observed when nontethered GluA1 and $\gamma-8$ subunits are coexpressed (Fig. $1 A_{1}, A_{2}, C$ ). Because AMPA receptor tetramers preferentially assemble as dimer-of-dimers (Mansour et al., 2001), cotransfection of a GluA1/ $\gamma-8$ tandem with a free GluA subunit produces receptors with two TARPs per complex (Shi et al., 2009); channels produced by cotransfection of GluA1/ $\gamma$-8 plus GluA2 show linear $I / V$ relationship confirming incorporation of GluA2 (Fig. $1 B$ ). Interestingly, glutamateevoked currents from two-TARP-containing receptors displayed no resensitization, which is similar to evoked currents from 

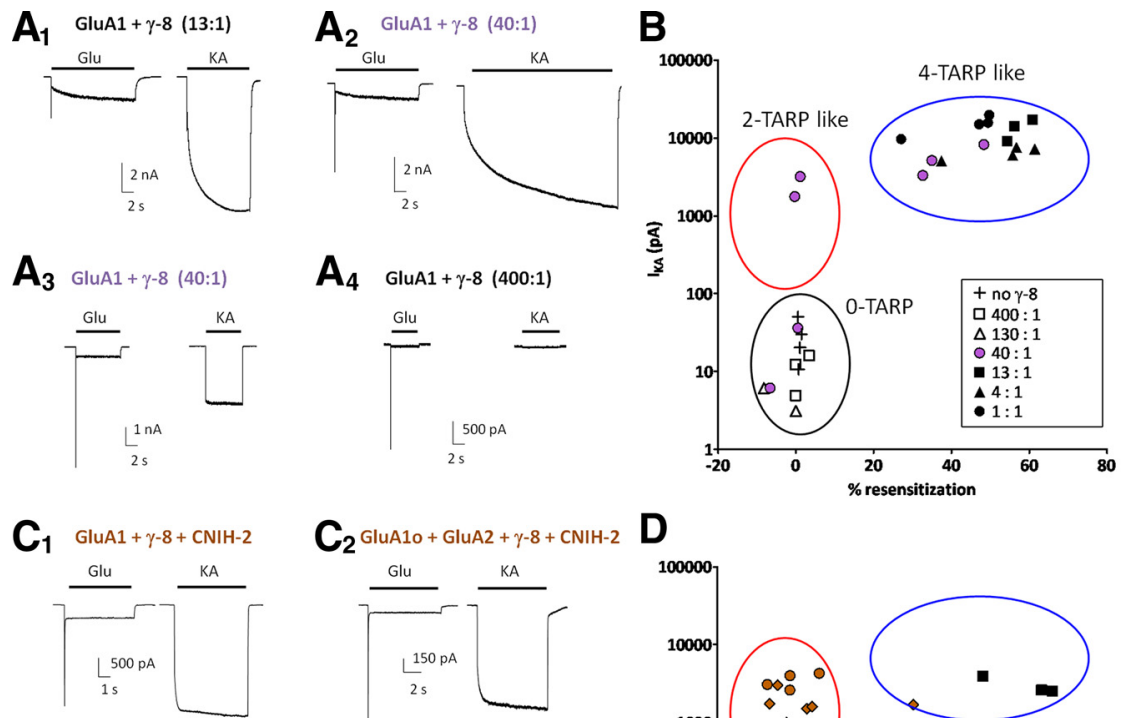

$\mathbf{C}_{2} \mathrm{GluA} 1 \mathrm{O}+\mathrm{GluA} 2+\gamma-8+\mathrm{CNIH}-2$
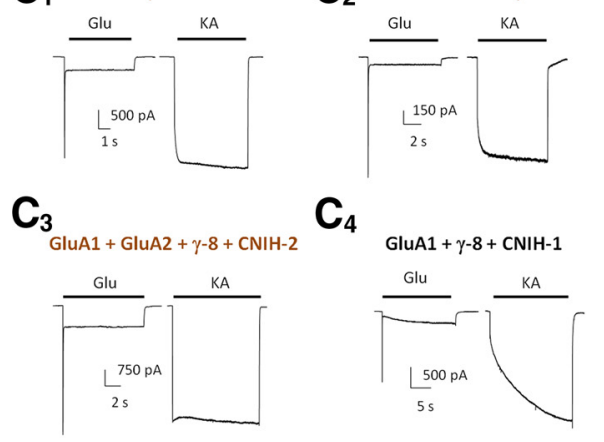

$\mathbf{C}_{4}$
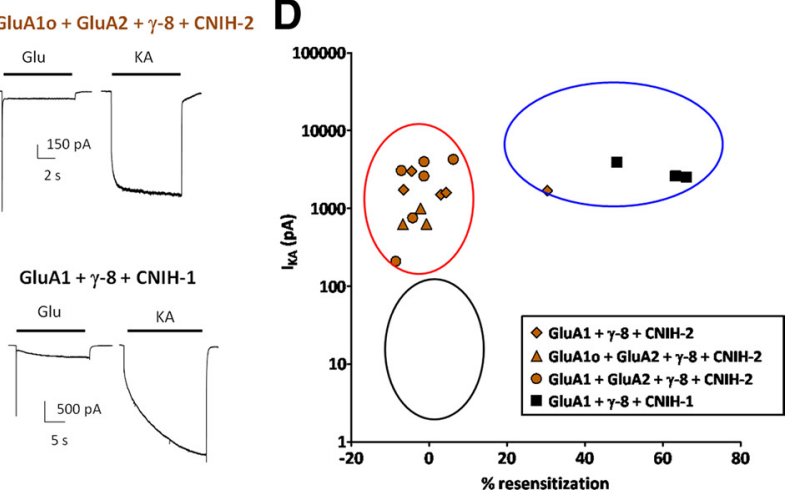

Figure 2. Transfected cells preferentially assemble into AMPA receptors with high TARP stoichiometry. $\boldsymbol{A}_{\mathbf{1}}-\boldsymbol{A}_{\mathbf{4}}$, Representative traces of kainate- and glutamate-evoked currents from HEK 293T cells cotransfected with various titrations of GluA1 and $\gamma-8$. Two examples from the GluA1: $\gamma-8(40: 1)$ transfection $\left(\boldsymbol{A}_{2}, \boldsymbol{A}_{3}\right)$ are shown to illustrate variability at this specific ratio. $B$, Comparison of the magnitude of kainate-evoked currents and degree of resensitization reveals that almost all titrations yielded receptors either having four-TARP-like properties (high KA current magnitude and high resensitization) or having no TARPs (low KA current magnitude and no resensitization). $\boldsymbol{C}_{\mathbf{1}}-\boldsymbol{C}_{\mathbf{4}}$, Representative traces of kainate- and glutamate-evoked currents from HEK 293T cells cotransfected $\gamma-8$ and $\mathrm{CNIH}-2$ with various GluA subunit combinations or GluA1 plus $\gamma-8$ plus CNIH-1. D. Comparison of the magnitude of kainate-evoked currents and degree of resensitization reveals that $\gamma-8$ plus CNIH-2 transfection yielded receptors having two-TARP-like properties (high KA current magnitude and no resensitization), whereas GluA1 plus $\gamma$-8 plus CNIH-1 resembled four-TARP-like receptors. GluA10 refers to the flop variant of the principal GluA1 AMPA receptor subunit.

acutely isolated hippocampal neurons or from HEK cells with either GluA subunit expressed alone (Fig. $1 A_{3}-A_{6}, C$ ).

Steady-state currents from these two-TARP-containing receptors were reduced in magnitude relative to the four-TARPcontaining receptors but were greater than those from GluA subunits alone (Fig. 1D). Importantly, restricting the number of $\gamma-8$ subunits per AMPA receptor complex had minimal impact on the ratio of kainate-evoked to glutamate-evoked steady-state currents $\left(I_{\mathrm{KA}} / I_{\mathrm{Glu}}\right)$, which was quantitatively similar to ratios from acutely isolated CA1 hippocampal neurons and was increased relative to kainate/glutamate current ratios from free GluA subunits expressed alone (Fig. $1 E$ ). This augmented $I_{\mathrm{KA}} / I_{\mathrm{Glu}}$ confirmed the presence of $\gamma-8$ in the two-TARP transfectants. Thus, resensitization is a kinetic signature of $\gamma$-8-containing AMPA receptors saturated with four TARPs per receptor complex.

\section{Recombinant AMPA receptors preferentially incorporate high $\gamma-8$ stoichiometry}

We next varied the ratio of transfected GluA1: $\gamma-8$ cDNAs from 1:1 to 400:1 with the goal of generating unlinked AMPA receptor/ TARP complexes of low TARP stoichiometry. To assess the presence and number of $\gamma-8$ subunits, we monitored the magnitude of kainate-evoked currents and the extent of glutamate-evoked resensitization, respectively (Fig. $2 A, B$ ). We found that all cells in transfections at GluA1: $\gamma-8$ ratios of 1:1, 4:1, and 13:1 showed large kainate-evoked currents and robust glutamate-evoked resensitization consistent with high-TARP stoichiometry AMPA receptors (Fig. $2 A_{1}, B$ ). At 130:1 and 400:1 ratios, all cells showed small kainate-evoked currents and no resensitization consistent with TARP-lacking AMPA receptors (Fig. $2 A_{4}, B$ ). From seven cells transfected at a 40:1 ratio, two showed large kainate-evoked currents and no resensitization (Fig. $2 A_{3}$ ) consistent with low-TARP stoichiometry AMPA receptors. This $40: 1$ ratio transfection also yielded three cells with high-TARP kinetics (Fig. $2 \mathrm{~A}_{2}$ ) and two cells with no TARP kinetics (Fig. $2 B$ ). These results suggest that transfection of even small amounts of $\gamma-8(1$ part in 13) into HEK cells yields only highTARP stoichiometry receptors. Whereas a specific ratio of GluA:TARP subunits (40:1) can yield some low-TARP receptors, the transition from no-TARP to high-TARP stoichiometry receptors in HEK cells occurs as a potent and steep function of $\gamma-8$ expression. Apparently, high-TARP stoichiometry is favored in transfected cells.

We previously reported that $\mathrm{CNIH}-2$ completely blocks resensitization in GluA1 plus $\gamma$-8-containing and partially reduces resensitization in $\mathrm{GluA} 1 / \gamma-8$ tandem AMPA receptors, while also maintaining large kainate-evoked currents (Kato et al., 2010). Here, we observed that CNIH-2 coexpression with $\gamma-8$ and various homomeric or heteromeric GluA subunit combinations reliably produced AMPA receptors that displayed no resensitization and high kainate-evoked current magnitudes (Fig. 2 $C_{1}-C_{3}, D$ ). Coexpression of GluA1 plus $\gamma-8$ with CNIH-1, an inactive homolog of CNIH-2 (Schwenk et al., 2009), produced AMPA receptors that exhibited the "fourTARP-like" phenotype of resensitization with a high kainate efficacy (Fig. $2 C_{4}, D$ ). Thus, cotransfection with $\mathrm{CNIH}-2$ creates AMPA receptors resembling low TARP $\gamma-8$ stoichiometry.

\section{TARP stoichiometry shapes hippocampal AMPA receptor CTZ pharmacology}

We next sought pharmacological signatures that were different between neuronal and recombinant receptors and potentially could be explained by changes in TARP/AMPA receptor stoichiometry. Previous reports have shown that CTZ potentiated KAevoked responses by $\sim 2$-fold in CA1 hippocampal neurons (Patneau et al., 1993), but only by $\sim 0.6$-fold in recombinantly expressed $\gamma$-8-containing receptors (Tomita et al., 2007). Recently, we showed that CTZ potentiated KA-evoked currents from heteromeric GluA1o/GluA2 AMPA receptors coexpressing $\gamma-8$ and CNIH-2 by $\sim 2$-fold (Kato et al., 2010). Here, we find that CTZ potentiates kainate-evoked currents by $\sim 10$-fold in $\gamma-8$ lacking AMPA receptors, by $\sim 2$-fold in two-TARP-containing receptors, and $<0.5$-fold in four-TARP-containing receptors (Fig. $\left.3 A_{1}-A_{3}, B\right)$. Importantly, in hippocampal neurons and in cells recombinantly expressing $\gamma-8$ plus $\mathrm{CNIH}-2$, we find that 
$\mathrm{A}_{1}$

GUMAD \& GUMA2 (O-TARP)

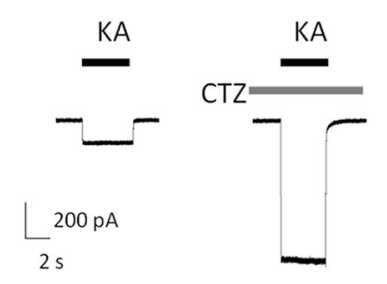

$\mathrm{A}_{4}$ GluA1 + GluA2 + $\gamma-8$

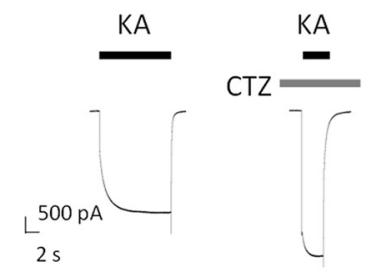

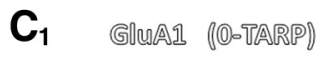
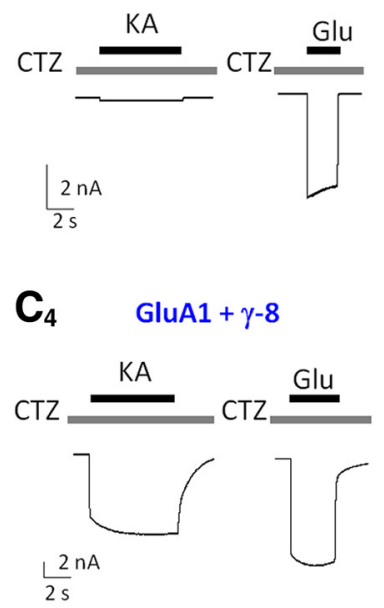

$\mathrm{A}_{2}$ GluA1/ $\gamma-8+$ GluA2 (2-TARP)

$\mathbf{A}_{3}$

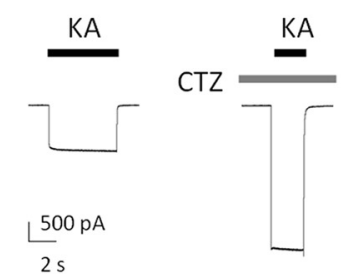

$\mathbf{A}_{5}$ GluA1 + GluA2 + $\gamma-8+\mathrm{CNIH}-2$

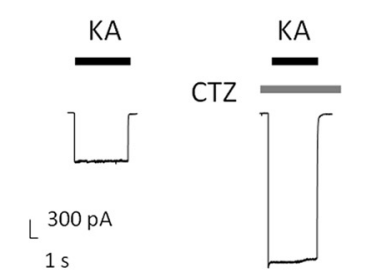

C2 GluA1 $/ \gamma-8+$ GluA2

(2-TARP)

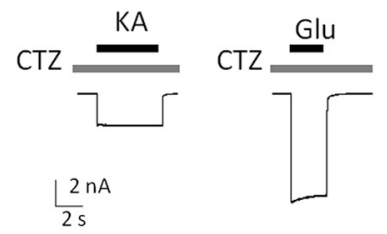

C 5 GluA1 + CNIH-2

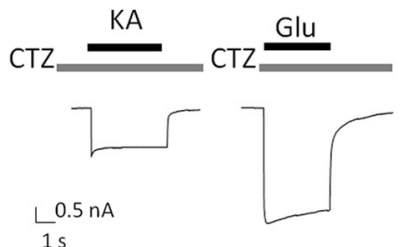

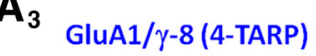

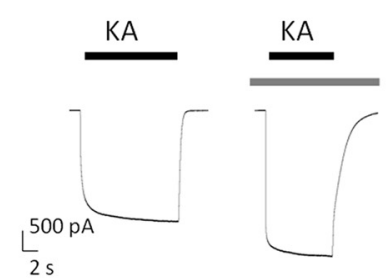

$A_{6}$

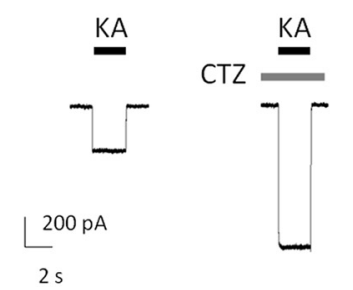

C $_{3}$ GluA1/ $\gamma-8$ (4-TARP)
B

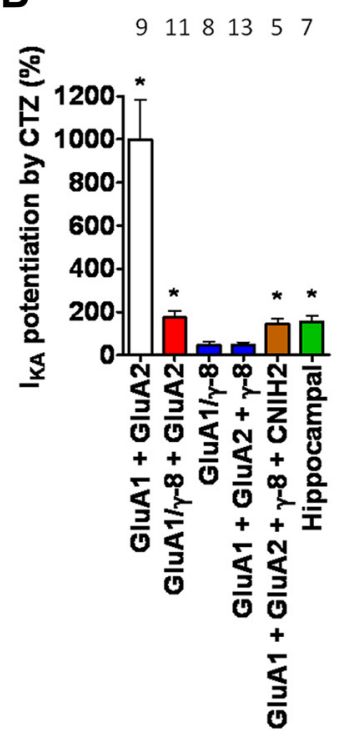

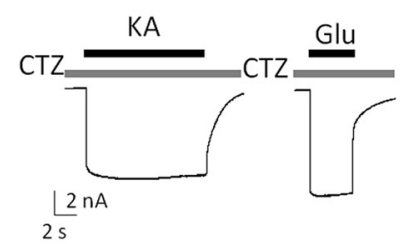

C $_{6}$ GluA1 $+\gamma-8+$ CNIH-2

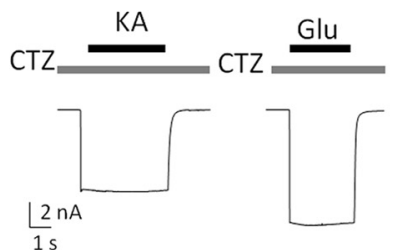

D $\quad \begin{array}{llllllll}8 & 4 & 4 & 9 & 5 & 8 & 5\end{array}$

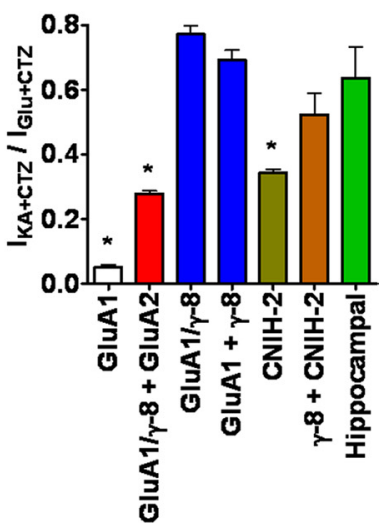

Figure 3. AMPA receptors coexpressing reduced $\gamma-8$ with CNIH-2 exhibit CA1 hippocampal neuron-like kainate/cyclothiazide pharmacology. $A_{1}-A_{6}$, Representative traces of kainate-evoked currents ( \pm CTZ) from HEK 293 T cells cotransfected with GluA1 plus GluA2 alone $\left(\boldsymbol{A}_{1}\right)$, GluA1/ $\gamma-8$ plus GluA2 ( $\boldsymbol{A}_{2}$; two TARPs), GluA1/ $\gamma-8\left(\boldsymbol{A}_{3}\right.$; four TARPs), GluA1 plus GluA2 plus $\gamma-8\left(\boldsymbol{A}_{4}\right)$, GluA1 plus GluA2 plus $\gamma-8$ plus CNIH-2 $\left(A_{5}\right)$, and from acutely isolated CA1 hippocampal neurons $\left(A_{6}\right)$. B, Quantification of CTZ potentiation of kainate-evoked currents reveals that reducing the number of $\gamma-8$ per AMPA receptor complex mimics the magnitude of (TZ potentiation observed in native CA1 hippocampal AMPA receptors. $\boldsymbol{C}_{\boldsymbol{1}}-\boldsymbol{C}_{\boldsymbol{6}}$, Representative traces of both kainate-evoked and glutamateevoked currents in the presence of (TZ from HEK 293T cells transfected with GluA1 alone $\left(\boldsymbol{C}_{\mathbf{1}}\right)$, tandem GluA1/ $\gamma-8$ plus GluA2 ( $\boldsymbol{C}_{2}$; two TARPs), tandem GluA1/ $\gamma-8\left(\boldsymbol{C}_{3}\right.$; four TARPs), nontethered GluA1 plus $\gamma-8\left(\boldsymbol{C}_{4}\right)$, GluA1 plus $\mathrm{CNIH}-2\left(\boldsymbol{C}_{5}\right)$, or GluA1 plus $\gamma-8$ plus $\mathrm{CNIH}-2\left(\boldsymbol{C}_{6}\right)$. D, Reducing the number of $\gamma-8$ subunits per AMPA receptor complex decreases $I_{\mathrm{KA}+\mathrm{CTZ}} / I_{\mathrm{Glu}}+\mathrm{CTZ}$, whereas coexpression of $\mathrm{CNIH}-2$ with GluA1 plus $\gamma-8$ maintains a high $I_{\mathrm{KA}+\mathrm{CTZ}} / I_{\mathrm{Glu}+\mathrm{CTZ}}$ ratio. Note that GluA1 plus $\mathrm{CNIH}-2$ shows a higher $I_{\mathrm{KA}+\mathrm{CTZ}} / I_{\mathrm{Glu}+\mathrm{CTZ}}$ ratio than GluA1 alone and that GluA1 plus $\gamma-8$ plus $\mathrm{CNIH}-2 \mathrm{more}$ closely resembles the CA1 hippocampal phenotype than two-TARP $\gamma$-8 AMPA receptors. ${ }^{*} p<0.05$ using Fisher's least significant difference (LSD) when compared with GluA1 plus GluA2 plus $\gamma$-8 $(\boldsymbol{B})$ or GluA1 plus $\gamma-8(\boldsymbol{D})$. Numbers of repetitions are indicated above the bar graphs. Summary data are mean \pm SEM.

CTZ potentiates kainate-evoked currents by $\sim 1.75$-fold, which resembles two-TARP-containing receptors (Fig. $3 A_{5}, A_{6}, B$ ).

To compare our results with other studies (Shi et al., 2009), we measured the ratio of kainate- to glutamate-evoked currents in the presence of CTZ. By including CTZ, we find the kainate/ glutamate ratio $\left(I_{\mathrm{KA}+\mathrm{CTZ}} / I_{\mathrm{Glu}+\mathrm{CTZ}}\right)$ of four $\gamma$-8-containing receptors is greater than two $\gamma$-8-containing receptors, agreeing with previously published experiments that pioneered use of tethered GluA1 $/ \gamma-8$ constructs to control stoichiometry (Shi et al., 2009) (Fig. $3 C_{2}, C_{3}, D$ ). Also agreeing with previous studies (Shi et al., 2010), we found that coexpressing CNIH-2 with GluA1 modestly increased the $I_{\mathrm{KA}+\mathrm{CTZ} /} I_{\mathrm{Glu}+\mathrm{CTZ}}$ ratio (Fig. $3 C_{5}, D$ ). Interestingly, we found that coexpression of CNIH-2 with nontethered GluA1 and $\gamma-8$ reproduced the CA1 hippocampal neuronal $I_{\mathrm{KA}+\mathrm{CTZ}} / I_{\mathrm{Glu}+\mathrm{CTZ}}$ ratio observed in our study, which is equivalent to the ratio previously reported (Shi et al., 2009) (Fig. $3 C_{6}, D$ ). Thus, although a reduction in $\gamma-8$ stoichiometry can reproduce some aspects of hippocampal neuron pharmacology, complete recapitulation of CA1 hippocampal neuron pharmacology also requires $\mathrm{CNIH}-2$.

\section{CNIH-2 reduces the number of TARP subunits in AMPA receptor complexes}

These pharmacological findings raise two distinct possibilities: CNIH-2 reduces TARP stoichiometry or CNIH-2 coassembles 


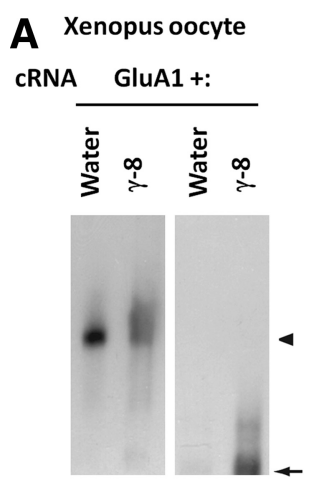

B Hippocampal lysate

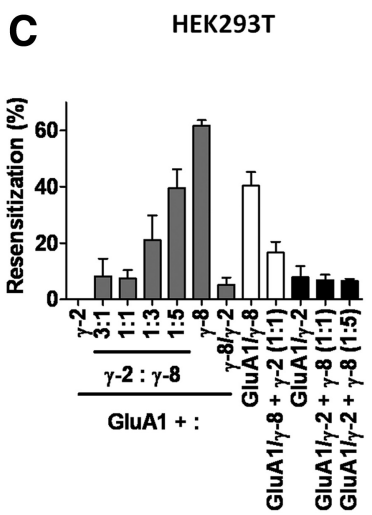

IB: GluA1 IB: $\gamma-8$

D

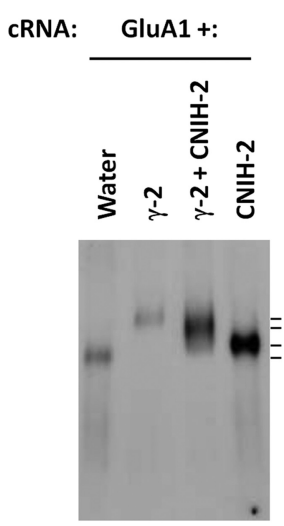

IB: GluA1
Xenopus oocyte

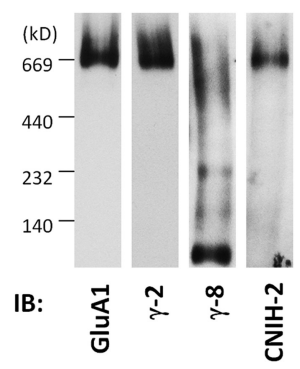

GluA1 +:

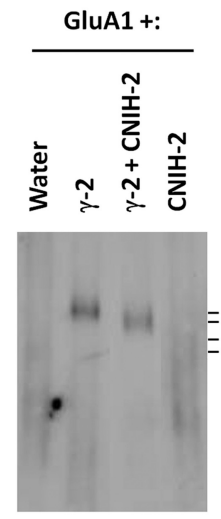

IB: TARPs
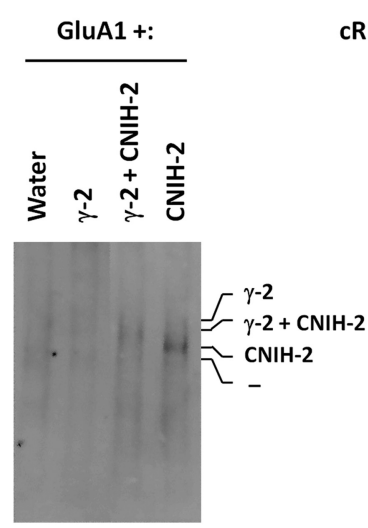

IB: CNIH-2

Figure 4. CNIH-2 reduces TARP stoichiometry in AMPA receptor complexes. A, 0ocytes were injected with cRNAs encoding GluA1 together with $\gamma-8$ as indicated, and native complexes were separated by blue native PAGE. Note that most of $\gamma-8$ does not comigrate with GluA1. The arrowhead denotes localization of the GluA1-containing tetrameric AMPA receptor complex, whereas the arrow denotes migration of TARP $\gamma-8$. B, Blue native PAGE of hippocampal membrane extracts reveals $\mathrm{CNIH}-2, \gamma-2$, and GluA1 but not $\gamma-8$ comigrate at a similar high molecule weight. C, $\gamma$-2 exhibits a higher functional affinity for AMPA receptors than $\gamma-8$. Quantification of resensitization reveals that only AMPA receptors expressing high $\gamma-8: \gamma-2$ ratios exhibit resensitization, and coexpression of GluA1 with a tandem construct linking $\gamma-2$ to $\gamma-8(\gamma-8 / \gamma-2)$ with GluA1 does not yield resensitizing currents. Coexpression of "free" $\gamma-2$ suppresses resensitization from the GluA1/ $\gamma-8$ tandem, whereas coexpression of free $\gamma-8$ does not induce resensitization from the GluA1/ $\gamma-2$ tandem. Summary data are mean \pm SEM. D, 0ocytes were injected with cRNAs encoding GluA1 together with $\gamma-2$ and/or $\mathrm{CNIH}-2$ as indicated, and native complexes were separated by blue native PAGE. Left panel, GluA1 immunoblot shows that addition of $\gamma$-2 and/or CNIH-2 produced AMPA receptor complexes that migrate higher than GluA1 alone. Importantly, addition of $\mathrm{CNIH}-2$ shifts down the native mass of GluA1 plus $\gamma-2$ complexes. Middle panel, $\gamma-2$ immunoblot demonstrates that coexpression of $\mathrm{CNIH}-2$ reduces the apparent molecular weight of $\gamma$-2-containing AMPA receptor complexes and CNIH-2 also reduces the intensity of the $\gamma$ - 2 band relative to the GluA1 band. Right panel, CNIH-2 immunoblot show that coexpression of $\gamma$-2 with $\mathrm{CNIH}-2$ increases the apparent molecular weight of $\mathrm{CNIH}-2$-containing AMPA receptor complexes and decreases the $\mathrm{CNIH}-2$ immunoblot intensity. $\boldsymbol{E}$, In oocyte blue native analyses, $\mathrm{CNIH}-2$ coexpression with tandem $\mathrm{GluA} 1 / \gamma-2$ does not reduce the apparent molecular weight compared with GluA1/ $\gamma$-2 expressed alone. The arrowhead denotes localization of the GluA1 subunit expresses alone, whereas the arrow denotes migration of the tandem GluA1/ $\gamma-2$ construct.

with four-TARP-saturated AMPA receptor complexes to modulate their biophysical properties. We used BN-PAGE to assess the mass of AMPA receptor complexes (Greger et al., 2003). Using a previously described oocyte expression system (Kim et al., 2010), we found that most of $\gamma-8$ did not comigrate with GluA1 when the two cRNAs were coinjected (Fig. 4A). This is curious as abundant evidence shows that these proteins associate and function together in hippocampal AMPA receptor complexes (Rouach et al., 2005; Fukaya et al., 2006). We therefore analyzed hippocampal lysates by BN-PAGE, and again $\gamma-8$ migrated in several discrete bands that were of lower molecular weight than the AMPA receptor complex. By contrast, GluA1, the prototypical TARP, $\gamma$-2, and CNIH-2 comigrate in a large-molecular-weight complex in hippocampus (Fig. 4B).
E Xenopus oocyte

We wondered why $\gamma$ - 8 might not adhere to AMPA receptor complexes in $\mathrm{BN}$ PAGE and hypothesized that $\gamma-8$ may have lower affinity than $\gamma$-2 for AMPA receptor complexes. To assess this, we titrated $\gamma$-2-containing AMPA receptor complexes with increasing amounts of $\gamma-8$ and monitored resensitization of glutamate-evoked currents. We observed that only at the highest ratios of $\gamma-8: \gamma-2$ tested was resensitization reliably detected (Fig. $4 C)$. We also constructed a tandem construct linking $\gamma-2$ and $\gamma-8(\gamma-2 / \gamma-8)$ and found that cotransfecting this construct together with GluA1 yielded non-resensitizing AMPA receptors. Furthermore, coexpression of $\gamma-2$ with the tandem GluA1/ $\gamma-8$ suppressed resensitization, indicating that $\gamma-2$ can outcompete even tethered $\gamma-8$. By contrast, expressing $\gamma-8$ with tandem GluA1/ $\gamma$-2 did not produce resensitization (Fig. 4C). These results suggest that $\gamma$-2 possesses a higher affinity than $\gamma-8$ for an AMPA receptor complex and may explain the greater stability of $\gamma-2$ in BNPAGE conditions. Therefore, we used the prototypical TARP, $\gamma$-2, for our additional BN-PAGE experiments.

Again using the Xenopus oocyte system, we monitored the assembly of AMPA receptors with $\gamma-2$ and $\mathrm{CNIH}-2$. When expressed alone, GluA1 migrated as a discrete large-molecular-mass complex that reflects the functional tetramer, consistent with a previous report (Fig. 4D) (Kim et al., 2010). Immunoblotting for GluA1 reveals that GluA1 plus $\gamma-2$ receptors migrate at a higher molecular weight than GluA1 alone. Importantly, CNIH-2 coexpression reduced the apparent molecular weight of the GluA1 band compared with extracts from GluAl plus $\gamma$ - 2 transfections (Fig. 4D). Furthermore, the apparent molecular weight and relative intensity of the $\gamma$ - 2 band in extracts from $\gamma$ - 2 plus $\mathrm{CNIH}-2$ coexpressing oocytes were also reduced relative to GluA1 plus $\gamma$-2 extracts (Fig. 4D). Expression of GluA1 plus CNIH-2 yielded a complex that was of still smaller apparent molecular mass and migrated just somewhat slower than GluA1 alone, but when coexpressed with $\gamma$ - 2 and GluA1, CNIH-2 migrated at an even higher molecular weight (Fig. 4D). Importantly, coexpression of CNIH-2 with the tandem GluA1/ $\gamma-2$ construct did not reduce the molecular weight of the complex relative to tandem GluA1/ $\gamma$-2 alone (Fig. $4 E$ ). Together, these data show that CNIH-2 assembles together with TARP and GluA1 proteins and that $\mathrm{CNIH}-2$ reduces the number of TARP subunits within an AMPA receptor complex.

\section{CNIH-2 modulates $\gamma$-7-containing AMPA receptor gating and kainate pharmacology}

We previously found that transfection of GluA1 with the type II TARP, $\gamma-7$, yields AMPA receptors that exhibit resensitizing cur- 
rents and a moderate $I_{\mathrm{KA}} / I_{\mathrm{Glu}}$ of $\sim 2$ (Kato et al., 2007). To assess effects of $\gamma-7$ stoichiometry on receptor gating and pharmacology, we constructed a GluA1/ $\gamma-7$ tandem construct. Expression of this tandem construct alone, which creates fourTARP-containing receptors, mimicked GluA1 plus $\gamma-7$ cotransfection and yielded resensitizing receptors displaying an $I_{\mathrm{KA}} / I_{\mathrm{Glu}}$ ratio of $\sim 2$ (Fig. $5 A_{3}, A_{4}, B-D$ ). Cotransfection of this tandem construct with GluA1, thereby reducing the stoichiometry to two TARPs, abolished resensitization. Importantly, these two $\gamma$-7-containing AMPA receptors show dramatically increased $I_{\mathrm{KA}} / I_{\mathrm{Glu}}$ ratios (Fig. $5 A_{2}, B-D$ ).

We also wondered whether $\mathrm{CNIH}-2$ might modify kinetics and pharmacology of $\gamma$-7-containing AMPA receptor complexes. Similar to its effects on $\gamma$-8-induced resensitization, CNIH-2 coexpression occluded $\gamma$-7-mediated resensitization (Fig. $5 A_{6}, B$ ). However, unlike $\gamma-8$ in which coexpression of CNIH-2 had no significant change on $I_{\mathrm{KA}} / I_{\text {Glu }}$ (Fig. 1E) (Kato et al., 2010), coexpression of $\mathrm{CNIH}-2$ with $\gamma$-7-containing AMPA receptors significantly increased $I_{\mathrm{KA}} /$ $I_{\mathrm{Glu}}$ (Fig. 5C). This synergistic effect of $\gamma-7$ and $\mathrm{CNIH}-2$ on $I_{\mathrm{KA}} / I_{\mathrm{Glu}}$ further establishes that both subunits can simultaneously modulate a single AMPA receptor complex.

We next evaluated the effects of coexpressing CNIH-2 with $\gamma-7$ and of reducing $\gamma$-7 stoichiometry on CTZ pharmacology. CTZ potentiated glutamate-evoked currents from GluA1 alone receptors by $\sim 400$-fold and this was reduced to $\sim 10$ to 20 -fold in cells transfected with GluA1 plus CNIH-2, GluA1 plus $\gamma-7$, GluA1 plus $\gamma-7$ plus CNIH-2, or tandem GluA1/ $\gamma-7$ (Fig. 5E). However, two-TARP $\gamma$-7-containing AMPA receptors (GluA1/ $\gamma-7$ plus GluA1) exhibited a striking increase in the magnitude of CTZ-mediated potentiation of glutamate-evoked currents relative to GluA1 plus $\gamma-7$ plus CNIH-2 receptors ( $\sim 200$ - vs $\sim 10$-fold, respectively) (Fig. $5 E$ ). Thus, $\gamma$-7-mediated resensitization and pharmacology are sensitive to both CNIH-2 and to the number of TARP subunits per AMPA receptor complex. However, receptors with reduced $\gamma-7$ stoichiometry show a differential glutamate/CTZ pharmacology relative to $\gamma-7$ plus CNIH-2.

To ascertain whether these unique biophysical properties of $\gamma$-7-containing AMPA receptors are dependent on the principal GluA subunit composition, we also studied GluA1/2 heteromers with $\mathrm{CNIH}-2$ and/or $\gamma$-7. We confirmed GluA2 incorporation via a linear $I-V$ relationship (data not shown). GluA1/2 coexpressed with $\mathrm{CNIH}-2$ possessed very low kainate/ glutamate ratios (Fig. $6 A_{4}, C$ ). Currents evoked from GluA1/2 plus $\gamma$-7 had low kainate/glutamate ratios but showed resensitizing kinetics (Fig. $6 A_{3}, B, C$ ). GluA1/2 heteromers in complex with both $\gamma-7$ and $\mathrm{CNIH}-2$ showed non-resensitizing responses and
A 2 GluA1/ $\gamma-7+$ GluA1 (2-TARP)

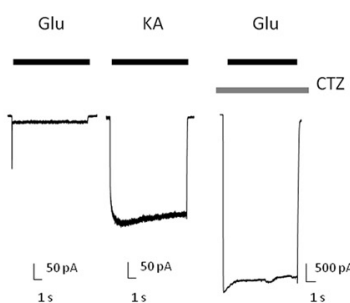

B

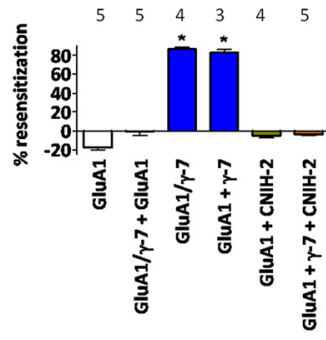

C

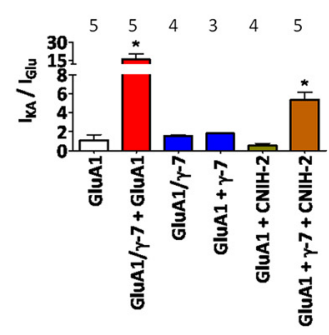

D
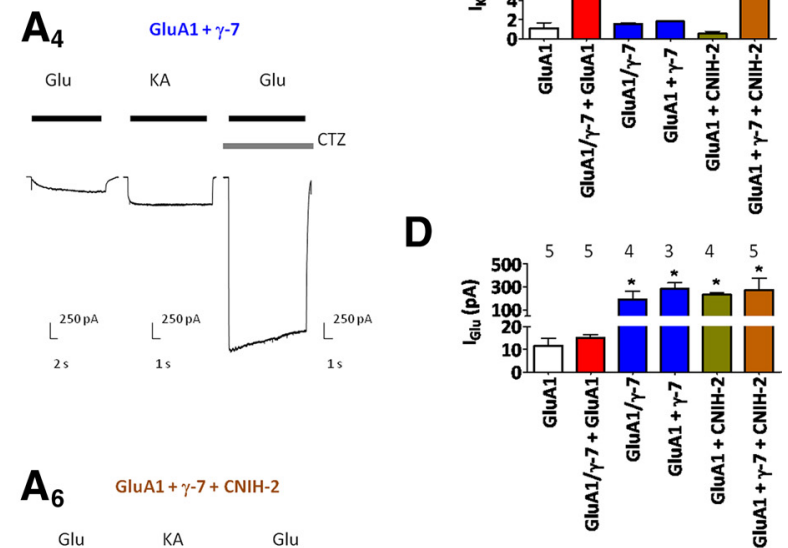

E

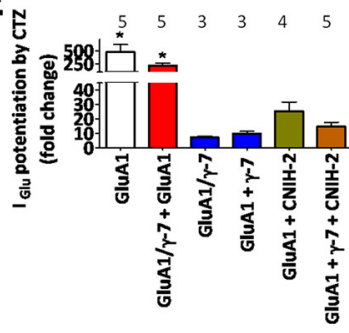

Figure 5. CNIH-2 modulates $\gamma-7$-containing AMPA receptor gating and pharmacology. $A_{1}-A_{6}$, Representative traces of kainate作 2 $\left(A_{6}\right)$. $B$, Quantification reveals that four-TARP — butnot two-TARP $-\gamma$-7-containing AMPA receptors exhibit resensitization.

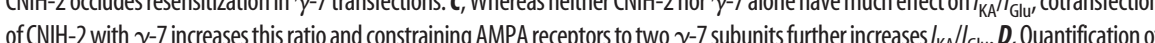
glutamate-evoked steady-state current from various $\gamma$-7 transfections. $\boldsymbol{E}$, Quantifying CTZ potentiation of glutamate-evoked currents reveals that $\gamma-7$ plus CNIH-2 and two-TARP $\gamma-7$ AMPA receptors exhibit strikingly different degrees of CTZ potentiation (low potentiation and high potentiation, respectively). ${ }^{*} p<0.05$ when compared with GluA1 alone $(\boldsymbol{B}-\boldsymbol{D})$ or GluA1 plus $\gamma-7(\boldsymbol{E})$. Numbers of repetitions are indicated above the bar graphs. Summary data are mean \pm SEM.

glutamate-evoked currents with modest potentiation by CTZ (Fig. $6 A_{5}, B, D, E$ ). Similar to GluA1 homomers containing two $\gamma$-7 subunits (Fig. 5 ), two-TARP $\gamma$-7-containing GluA1/2 heteromers have non-resensitizing glutamate-evoked currents with high kainate/glutamate ratios and robust CTZ-mediated potentiation of glutamate-evoked currents (Fig. $6 A_{2}, B-E$ ). Thus, $\gamma-7-$ containing AMPA receptor pharmacology and gating are more dependent on accessory subunit configuration rather than principal GluA isoform composition.

AMPA receptors in stargazer Purkinje neurons resemble low $\gamma-7$ stoichiometry

To determine how these features in heterologous cells compare with native $\gamma$-7-containing AMPA receptors, we evaluated cerebellar Purkinje neurons, which express $\gamma-7, \gamma-2$, and CNIH-2 (Lein et al., 2007; Schwenk et al., 2009). Previous studies showed 

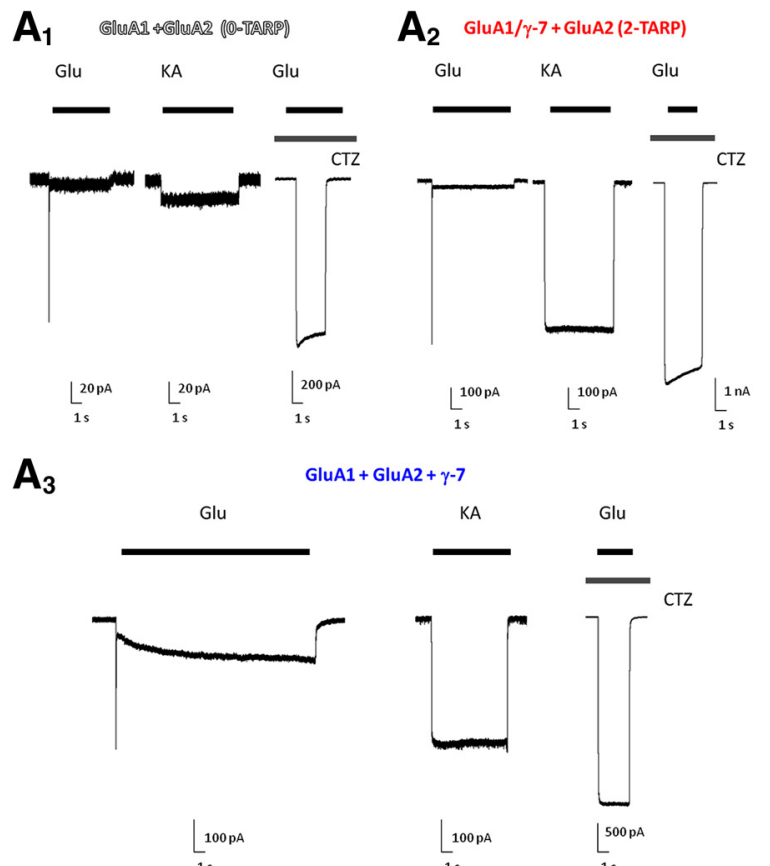

GluA1 + GluA2 + $\gamma-7$

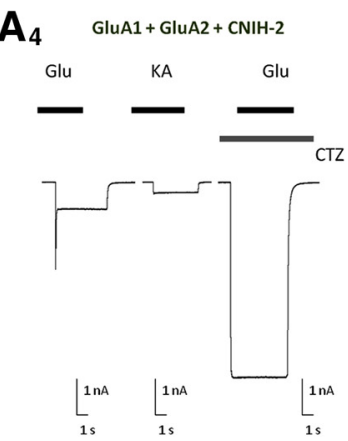

$\mathbf{A}_{5}$
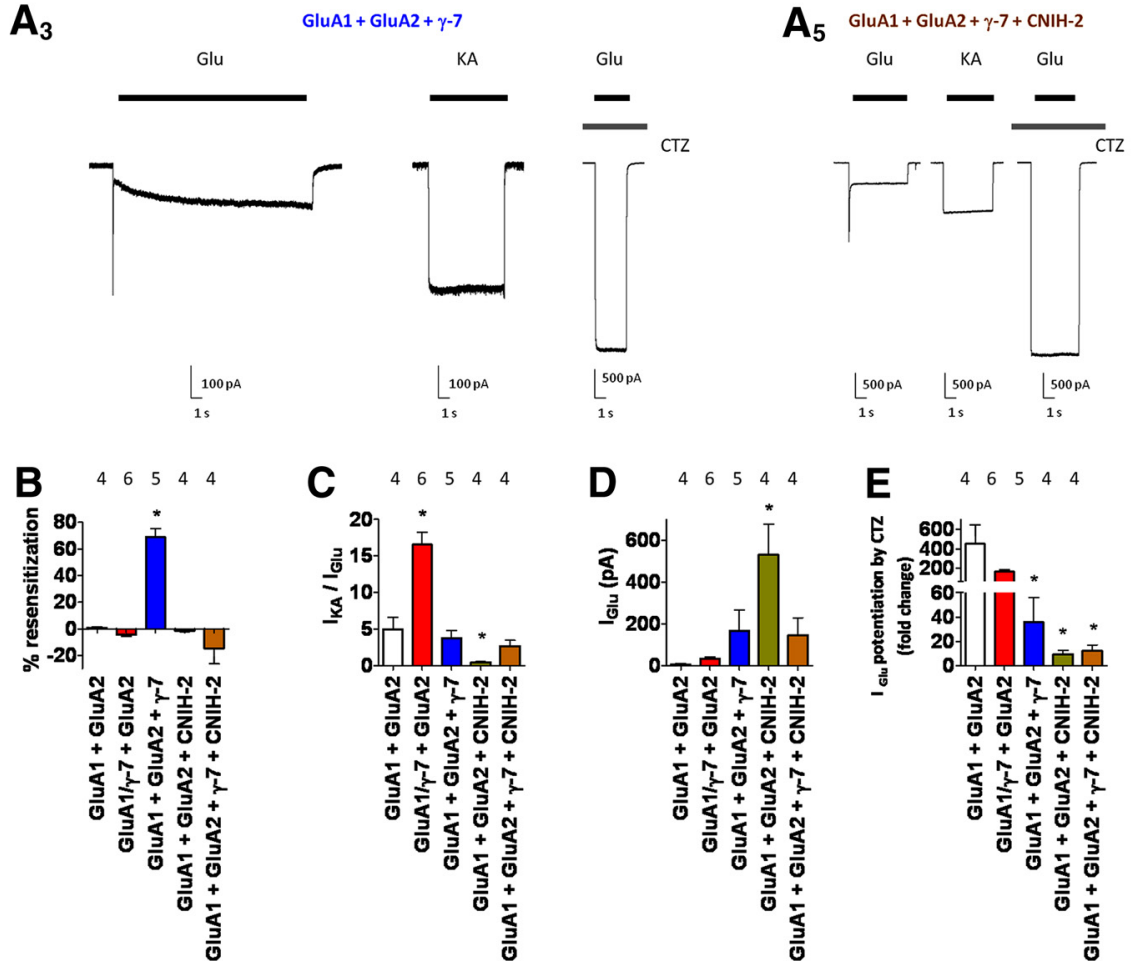

Figure 6. $\quad \gamma-7$ and $\mathrm{CNIH}-2$ interact to regulate gating and pharmacology of GluA1/2 heteromers. $A_{1}-A_{4}$, Representative traces of kainate-, glutamate-, and CTZ plus glutamate-evoked responses from cells expressing GluA1/2 $\left(A_{7}\right)$, tandem GluA1/ $\gamma-7$ plus GluA2 ( $\boldsymbol{A}_{2}$; two TARPs), GluA1/2 plus (NIH-2 $\left(\boldsymbol{A}_{3}\right)$, GluA1/2 plus $\gamma-7\left(\boldsymbol{A}_{4}\right)$, or GluA1/2 plus $\gamma-7$ plus $\left(\mathrm{NIH}-2\left(\boldsymbol{A}_{5}\right)\right.$. Quantification of resensitization $(B)$ and $I_{\mathrm{KA}} / I_{\mathrm{Glu}}$ ratios $(\boldsymbol{C})$ from the GluA1/2 cotransfectants reveals that $\gamma$-7-induced resensitization is blocked by either $\mathrm{CNIH}-2$ or by reducing $\gamma-7$ stoichiometry. Only reducing $\gamma-7$ stoichiometry generates high $I_{\mathrm{KA}} / I_{\mathrm{Glu}}$ ratios. D, Quantification of glutamate-evoked steady-state current from various $\gamma-7$ transfections. $E$, Quantifying CTZ potentiation of glutamate-evoked currents reveals that, among the accessory protein-containing AMPA receptor complex configurations, only two-TARP $\gamma$-7containing AMPA receptors exhibit strikingly high CTZ potentiation of glutamate-evoked currents. ${ }^{*} p<0.05$ when compared with GluA1/2 alone (Fisher's LSD). Summary data are mean \pm SEM.

that synaptic AMPA receptor currents in Purkinje neurons are reduced $50-70 \%$ in stargazer mice (Hashimoto et al., 1999; Menuz and Nicoll, 2008) and that $\gamma-2 / \gamma-7$ double-knock-out mice show a $\sim 90 \%$ reduction (Yamazaki et al., 2010). Analysis of acutely isolated Purkinje neurons from stargazer mice, which lack $\gamma$-2, therefore provides a system to study neuronal $\gamma-7$ containing AMPA receptors. As previously reported (Menuz and Nicoll, 2008), we find that extrasynaptic AMPA receptor responses elicited by glutamate plus CTZ are similar in stargazer and wild-type Purkinje neurons (Fig. 7C, D,F). Unexpectedly, however, we found a dramatic reduction in steady-state glutamat ked currents in stargazer Purkinje neurons (Fig. $7 A, B, E$ ). Importantly, when normalized to the glutamate-evoked current magnitude, CTZ potentiates stargazer Purkinje neuron glutamate-evoked currents $\sim 150-200$-fold, which was similar in magnitude to the potentiation observed with low $\gamma$-7-containing AMPA receptors (Fig. $7 E, F)$. Furthermore, extrasynaptic Purkinje neuron AMPA receptors from stargazer mice display a high $I_{\mathrm{KA}} / I_{\mathrm{Glu}}$ ratio of $\sim 17$ and exhibit no resensitization (Fig. $7 G, H)$. This unique combination of features (very high $I_{\mathrm{KA}} / I_{\mathrm{Glu}}$ ratio and very high CTZ potentiation) can be mimicked only by recombinant AMPA receptors containing a low $\gamma$-7 stoichiometry without coexpression of CNIH-2.

\section{Hippocampal CNIH-2 surface expression requires $\gamma-8$}

We previously showed that CNIH-2 is present on the membrane surface in the hippocampus where it modulates synaptic function (Kato et al., 2010). By contrast, our data in stargazer Purkinje neurons suggest that $\mathrm{CNIH}-2$ effects may be restricted internally to control $\gamma-7$ stoichiometry. Because $\gamma-8$ is highly expressed in CA1 hippocampal neurons and stabilizes hippocampal CNIH-2 protein expression (Rouach et al., 2005), we wondered whether $\gamma-8$ also modulates $\mathrm{CNIH}-2$ surface expression. Using a cell-impermeant biotinylation reagent, we compared CNIH-2 surface levels in hippocampi from wild-type and $\gamma-8$ knock-out mice. As previously published, we found that GluA1/2, $\gamma-8$, and CNIH-2 are expressed on the surface of hippocampal slices, whereas internally expressed $\beta$-tubulin and synaptophysin are not (Fig. $8 A$ ). We also confirmed previous reports that total GluA1 (Rouach et al., 2005) and CNIH-2 levels (Kato et al., 2010) are reduced in $\gamma-8$ knock-out hippocampus (Fig. $8 \mathrm{~A}$ ). Interestingly, we found that the residual CNIH-2 in $\gamma-8$ knock-out hippocampus is depleted from the cell surface (Fig. $8 A, C)$. By contrast, knock-out of $\gamma-8$ did not abolish surface expression of the residual GluA1/2 proteins (Fig. $8 A, C$ ). Thus, $\gamma-8$ appears necessary for the surface trafficking of $\mathrm{CNIH}-2$ within the

hippocampus.

Previous reports have indicated that $\mathrm{CNIH}-2$ does not traffic to the surface in cerebellar granule neurons (Shi et al., 2010). In support, our AMPA receptor gating and pharmacological data from stargazer Purkinje neurons resemble low stoichiometry $\gamma$-7-containing AMPA receptors (Figs. 6, 7). Assessing for CNIH-2 surface expression in stargazer mouse cerebella, we observed that $\mathrm{CNIH}-2$ resided almost exclusively within cells, whereas GluA1, GluA2, and $\gamma-7$ were expressed at the plasma membrane (Fig. $8 B, D$ ).

\section{Discussion}

This study demonstrates that resensitization observed in $\gamma$-7-and $\gamma$-8-containing AMPA receptor complexes requires a high stoichiometry of these TARPs. CNIH-2 reduces TARP stoichiometry 
and produce receptors with distinctive pharmacologies. Recombinant AMPA receptors containing low $\gamma-7$ stoichiometry replicate the gating and pharmacology observed in stargazer cerebellar Purkinje neurons, whereas properties of hippocampal CA1 neurons are mimicked by coexpression of both $\gamma-8$ and $\mathrm{CNIH}-2$ in surface AMPA receptor complexes. Indeed, CNIH-2 occurs on the neuronal surface in hippocampus in a $\gamma-8$ dependent manner but not in cerebellum, which lacks $\gamma-8$. Together, these results indicate that $\mathrm{CNIH}-2$ modulates the stoichiometry of TARPs in diverse neuronal types but that CNIH-2 associates at the cell surface only with specific TARPcontaining AMPA receptors.

\section{CNIH-2 modulates GluA/TARP subunit assembly to regulate channel gating} We reported previously that glutamateevoked currents from recombinant AMPA receptors containing $\gamma-4,-7$, or -8 show resensitization, a triphasic kinetic signature that involves delayed accrual of current after initial receptor desensitization (Kato et al., 2010). This resensitization is observed only from certain TARP-containing recombinant AMPA receptors but not from native neurons (Kato et al., 2010). Here, we characterized these peculiar resensitization kinetics and found they occur only in $\gamma-8$ - and $\gamma$-7-containing AMPA receptor complexes that are saturated with four TARPs per complex.

Recent studies investigated the stoichiometry of TARPs within both native and recombinant AMPA receptors and assessed the effect TARP stoichiometry has on AMPA receptor gating and pharmacology (Shi et al., 2009; Kim et al., 2010). Analysis of AMPA receptor complexes from injected oocytes shows that stoichiometry is not fixed and up to four TARPs can associate within an AMPA receptor complex (Kim et al., 2010). Similarly, TARP stoichiometry in neurons is variable (Shi et al., 2009) and can be increased in certain neuronal types by TARP overexpression (Milstein et al., 2007). Our study in transfected cells shows titrations of $\gamma-8$ with GluA subunits could not reproducibly yield receptors showing neuronal-like features. Heterologous assembly preferentially formed receptors with high $\gamma-8$ stoichiometry (high kainate efficacy with resensitization). These data agree with an oocytes expression study that also found a steep shift in TARP/ GluA1 assembly using GFP-tagged stargazin cotransfected with GluA1 (Kim et al., 2010).

Because CA1 hippocampal neurons exhibit high kainate efficacy with no resensitization, a neuronal process not present in recombinant cells must regulate GluA/TARP assembly. Recently, we reported that $\mathrm{CNIH}-2$ blunts resensitization while maintaining the $\gamma$-8-dependent pharmacology of CA1 hippocampal neurons (Kato et al., 2010), suggesting that CNIH-2 could be the relevant factor. Indeed, using blue native gels, we find that CNIH-2 reduces the molecular weight of TARP-containing AMPA receptor complexes. Furthermore, these native gels show that CNIH-2 is present in the GluA/TARP complex. This finding supports previously reported data suggesting that $\mathrm{CNIH}-2$ and TARPs can interact with a common GluA receptor (Kato et al., 2010). CNIH-2 also promotes trafficking of AMPA receptors through the endoplasmic reticulum/Golgi apparatus (Schwenk et al., 2009; Shi et al., 2010). Thus, CNIH-2 serves multiple aspects of GluA/TARP assembly and trafficking.

\section{CNIH-2 modulates AMPA receptor gating and pharmacology} in diverse neuronal types

Immunohistochemical and in situ hybridization analyses show that Purkinje neurons are enriched with $\gamma-2, \gamma-7$, and CNIH-2 (Lein et al., 2007; Schwenk et al., 2009). The very high $I_{\mathrm{KA}} / I_{\mathrm{Glu}}$ for AMPA receptors in cerebellar Purkinje neurons from stargazer mice was unexpected because previous studies showed that $\gamma-7$ (Kato et al., 2007) or CNIH-2 (Shi et al., 2010) only modestly increased $I_{\mathrm{KA}} / I_{\mathrm{Glu}}$. Coexpression of both $\gamma-7$ and CNIH-2 increases $I_{\mathrm{KA}} / I_{\mathrm{Glu}}$, but not to the level found in stargazer Purkinje neurons. Recapitulating the very high $I_{\mathrm{KA}} / I_{\mathrm{Glu}}$ level found in stargazer Purkinje neurons was achieved only by constraining AMPA receptors to contain two $\gamma-7$ subunits per AMPA receptor complex. Importantly, we found that $\mathrm{CNIH}-2$ does not occur on the surface in cerebellar slices. Indeed, stargazer Purkinje neuronal AMPA receptor gating and pharmacology was closely recapitulated by recombinant receptor containing two $\gamma-7$ subunits.

We also observed that stargazer Purkinje neurons show only a modest change in whole-cell currents elicited by glutamate plus CTZ but a dramatic reduction in currents elicited by glutamate alone. This suggests a primary role for $\gamma-2$ in regulating gating rather than trafficking of surface AMPA receptors in cerebellar Purkinje neurons. This differs from cerebellar granule neurons where $\gamma-2$ plays a fundamental role in both surface trafficking and gating AMPA receptors (Hashimoto et al., 1999; Chen et al., 2000; Rouach et al., 2005; Fukaya et al., 2006). Of interest, we find no difference in the surface-to-internal ratio of the residual AMPA receptors in $\gamma-8$ knock-out hippocampus. One explanation is that not all surface AMPA receptors in hippocampus contain a TARP, or alternatively that other TARPs traffic the residual AMPA receptors. Together, these unexpected findings underscore TARP isoform and cell type dependence for surface trafficking of AMPA receptors.

We recently observed that recombinant expression of GluA subunits with both $\gamma-8$ and $\mathrm{CNIH}-2$ closely recapitulates prop- 
A
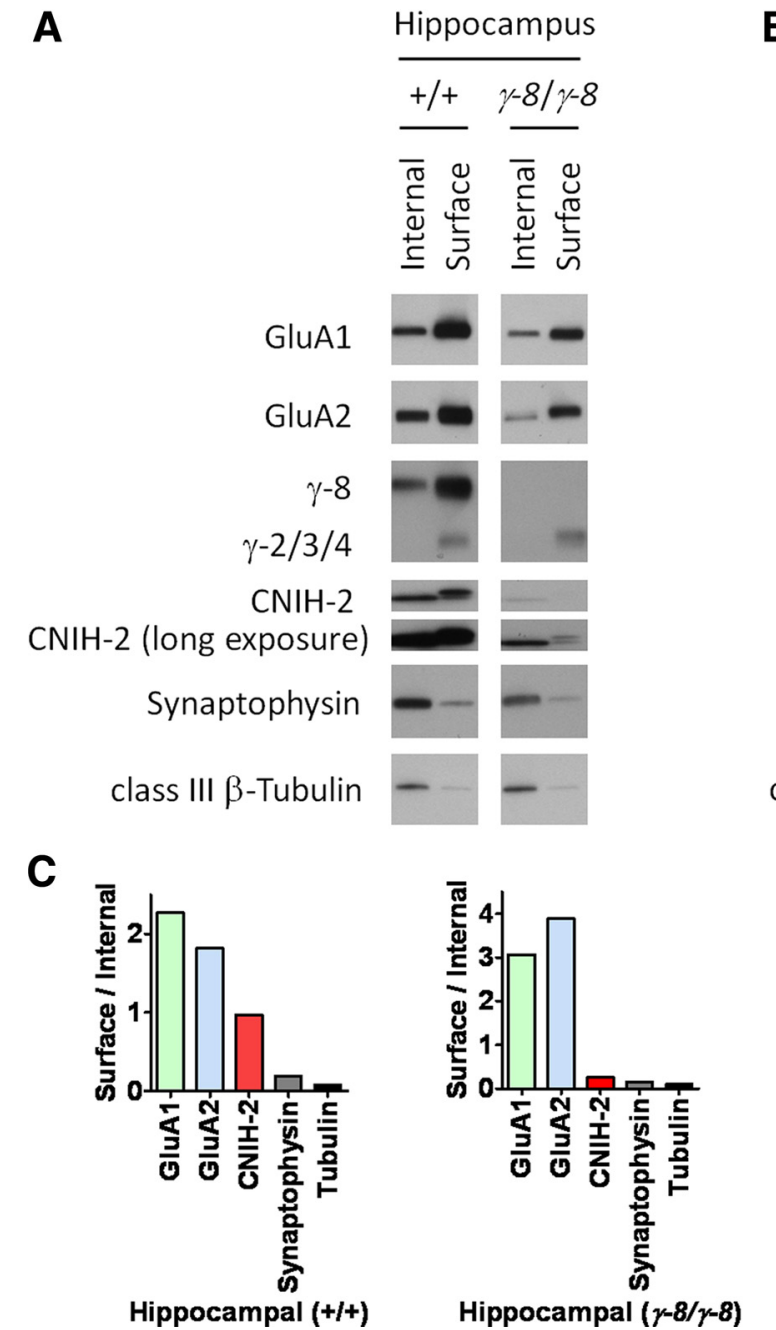

-๑
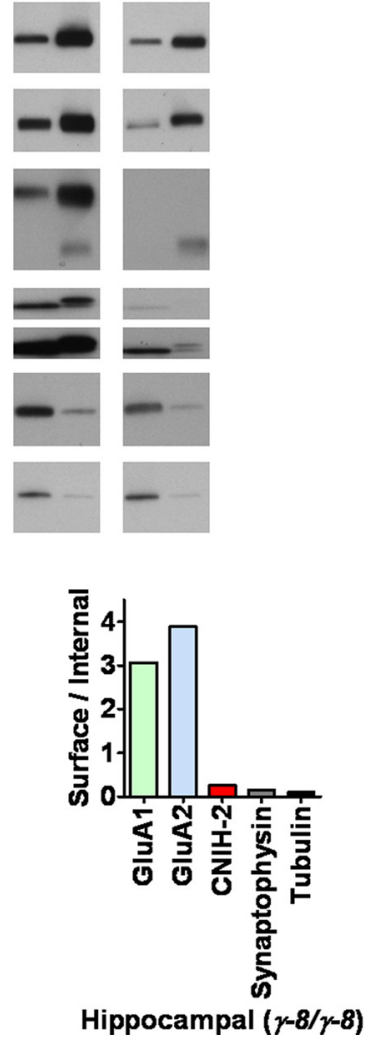

B

Figure 8. Surface expression of neuronal CNIH-2 requires $\gamma-8$. $A$, In wild-type mouse hippocampus, GluA1, GluA2, TARPs, and CNIH-2 occur on the surface. Knock-out of $\gamma-8(\gamma-8 / \gamma-8)$ reduced total levels of GluA1, GluA2, and CNIH-2 while selectively depleting CNIH-2 from the surface in hippocampal slices. $\boldsymbol{B}$, In cerebella from stargazer mice (stg/stg), CNIH-2 resides almost exclusively within cells, whereas GluA1, GluA2, and $\gamma-7$ are present on the surface. The asterisk $\left({ }^{*}\right)$ denotes a nonspecific band in biotinylated lysates that reacts with the secondary antibody. C, Quantification reveals a reduction in the surface expression of CNIH-2 in extracts from the $\gamma$-8 knock-out hippocampus, whereas surface GluA isoform expression remains equivalent, relative to wild-type hippocampus. D, CNIH-2 surface expression in stargazer cerebellum is absent, whereas GluA isoforms and $\gamma$-7 are present at the plasma membrane. For both hippocampal and cerebellar surface biotinylation experiments, $\beta$-tubulin and synaptophysin served as internal controls for surface expression.

erties of hippocampal CA1 AMPA receptors, but the mechanism for functional interaction of $\gamma-8$ and $\mathrm{CNIH}-2$ was unclear (Kato et al., 2010). Data here show that CNIH-2 acts on TARPcontaining receptors to modulate TARP/AMPA receptor stoichiometry, and this alteration in TARP stoichiometry accounts for many of the observed native neuronal phenotypes. Reducing the stoichiometry of $\gamma$-8 in AMPA receptor complexes, however, did not produce AMPA receptors that comprehensively mimicked CA1 hippocampal neuron pharmacology. Specifically compared with four-TARP $\gamma$-8 receptors, $I_{\mathrm{KA}} / I_{\mathrm{Glu}}$ in the presence of CTZ was reduced in two-TARP $\gamma$-8-containing receptors. This two-TARP $I_{\mathrm{KA}+\mathrm{CTZ}} / I_{\mathrm{Glu}+\mathrm{CTZ}}$ value matched previous findings with recombinant constructs and differs from CA1 hippocampal neurons, which, in this regard, resemble four-TARP $\gamma$-8 AMPA receptors (Shi et al., 2009). Based on these results, others concluded that CA1 hippocampal neurons contain four $\gamma$-8 subunits per AMPA receptor complex (Shi et al., 2009). However, resensitization is a kinetic signature of four-TARP $\gamma-8$ receptors, and the absence of try (Sobolevsky et al., 2009). As up to four TARPs can bind to AMPA receptor complexes (Kim et al., 2010), these auxiliary subunits likely interact in part with the fourfold symmetric transmembrane region. The number of $\mathrm{CNIH}-2$ that binds to AMPA receptors also remains uncertain. Because $\mathrm{CNIH}-2$ is a very small protein comprised in large part of transmembrane domains, it too likely interacts in part with GluA transmembrane regions.

The twofold symmetric extracellular domain of tetrameric AMPA receptors exhibits pairs of larger- and smaller-sized grooves for potential interaction with accessory subunits (Sobolevsky et al., 2009). TARP modulation of channel function is mediated by its large extracellular domain (Tomita et al., 2005), whereas a small extracellular domain in $\mathrm{CNIH}-2$ mediates its augmentation of glutamate-evoked currents and occlusion of resensitization (Kato et al., 2010). Thus, one might hypothesize that $\mathrm{CNIH}-2$ interacts with the smaller extracellular grooves in GluA and thereby favorably competes with two of the four TARP subunits to reduce TARP stoichiometry. Future structural studies of 
AMPA receptors containing TARP and CNIH-2 proteins will provide decisive insight regarding the molecular details for these interactions and how they regulate AMPA receptor gating.

Multiple accessory proteins modulating channel glutamate receptor function appears evolutionarily conserved. Functional activity for glutamate receptor subunit GLR1 in Caenorhabditis elegans requires both a TARP and a CUB domain-containing protein, suppressor of Lurcher-1 (SOL-1) (Wang et al., 2008). Whether a CNIH homolog also occurs in C. elegans and controls TARP/SOL-1 stoichiometry also remains unknown. As differential assembly of AMPA receptors can profoundly modulate synaptic function (Cho et al., 2007; Milstein et al., 2007), it will be important to understand how this process is regulated and relates to physiological and disease states.

\section{References}

Chen L, Chetkovich DM, Petralia RS, Sweeney NT, Kawasaki Y, Wenthold RJ, Bredt DS, Nicoll RA (2000) Stargazin regulates synaptic targeting of AMPA receptors by two distinct mechanisms. Nature 408:936-943.

Cho CH, St-Gelais F, Zhang W, Tomita S, Howe JR (2007) Two families of TARP isoforms that have distinct effects on the kinetic properties of AMPA receptors and synaptic currents. Neuron 55:890-904.

Collingridge GL, Olsen RW, Peters J, Spedding M (2009) A nomenclature for ligand-gated ion channels. Neuropharmacology 56:2-5.

Dingledine R, Borges K, Bowie D, Traynelis SF (1999) The glutamate receptor ion channels. Pharmacol Rev 51:7-61.

Fukaya M, Yamazaki M, Sakimura K, Watanabe M (2005) Spatial diversity in gene expression for VDCCgamma subunit family in developing and adult mouse brains. Neurosci Res 53:376-383.

Fukaya M, Tsujita M, Yamazaki M, Kushiya E, Abe M, Akashi K, Natsume R, Kano M, Kamiya H, Watanabe M, Sakimura K (2006) Abundant distribution of TARP gamma- 8 in synaptic and extrasynaptic surface of hippocampal neurons and its major role in AMPA receptor expression on spines and dendrites. Eur J Neurosci 24:2177-2190.

Greger IH, Khatri L, Kong X, Ziff EB (2003) AMPA receptor tetramerization is mediated by $\mathrm{Q} / \mathrm{R}$ editing. Neuron 40:763-774.

Hashimoto K, Fukaya M, Qiao X, Sakimura K, Watanabe M, Kano M (1999) Impairment of AMPA receptor function in cerebellar granule cells of ataxic mutant mouse stargazer. J Neurosci 19:6027-6036.

Hollmann M, Heinemann S (1994) Cloned glutamate receptors. Annu Rev Neurosci 17:31-108.

Kato AS, Zhou W, Milstein AD, Knierman MD, Siuda ER, Dotzlaf JE, Yu H, Hale JE, Nisenbaum ES, Nicoll RA, Bredt DS (2007) New transmembrane AMPA receptor regulatory protein isoform, $\gamma$-7, differentially regulates AMPA receptors. J Neurosci 27:4969-4977.

Kato AS, Siuda ER, Nisenbaum ES, Bredt DS (2008) AMPA receptor subunit-specific regulation by a distinct family of type II TARPs. Neuron 59:986-996.

Kato AS, Gill MB, Ho MT, Yu H, Tu Y, Siuda ER, Wang H, Qian YW, Nisenbaum ES, Tomita S, Bredt DS (2010) Hippocampal AMPA receptor gating controlled by both TARP and cornichon proteins. Neuron 68:1082-1096.

Kim KS, Yan D, Tomita S (2010) Assembly and stoichiometry of the AMPA receptor and transmembrane AMPA receptor regulatory protein complex. J Neurosci 30:1064-1072.

Lein ES, Hawrylycz MJ, Ao N, Ayres M, Bensinger A, Bernard A, Boe AF, Boguski MS, Brockway KS, Byrnes EJ, Chen L, Chen L, Chen TM, Chin MC, Chong J, Crook BE, Czaplinska A, Dang CN, Datta S, Dee NR, et al. (2007) Genome-wide atlas of gene expression in the adult mouse brain. Nature 445:168-176.

Mansour M, Nagarajan N, Nehring RB, Clements JD, Rosenmund C (2001)
Heteromeric AMPA receptors assemble with a preferred subunit stoichiometry and spatial arrangement. Neuron 32:841-853.

Mayer ML, Armstrong N (2004) Structure and function of glutamate receptor ion channels. Annu Rev Physiol 66:161-181.

Menuz K, Nicoll RA (2008) Loss of inhibitory neuron AMPA receptors contributes to ataxia and epilepsy in stargazer mice. J Neurosci 28:1059910603.

Milstein AD, Zhou W, Karimzadegan S, Bredt DS, Nicoll RA (2007) TARP subtypes differentially and dose-dependently control synaptic AMPA receptor gating. Neuron 55:905-918.

Morimoto-Tomita M, Zhang W, Straub C, Cho CH, Kim KS, Howe JR, Tomita S (2009) Autoinactivation of neuronal AMPA receptors via glutamate-regulated TARP interaction. Neuron 61:101-112.

Moss FJ, Dolphin AC, Clare JJ (2003) Human neuronal stargazin-like proteins, gamma2, gamma3 and gamma4; an investigation of their specific localization in human brain and their influence on CaV2.1 voltagedependent calcium channels expressed in Xenopus oocytes. BMC Neurosci 4:23.

Patneau DK, Vyklicky L Jr, Mayer ML (1993) Hippocampal neurons exhibit cyclothiazide-sensitive rapidly desensitizing responses to kainate. J Neurosci 13:3496-3509.

Rouach N, Byrd K, Petralia RS, Elias GM, Adesnik H, Tomita S, Karimzadegan S, Kealey C, Bredt DS, Nicoll RA (2005) TARP gamma-8 controls hippocampal AMPA receptor number, distribution and synaptic plasticity. Nat Neurosci 8:1525-1533.

Schwenk J, Harmel N, Zolles G, Bildl W, Kulik A, Heimrich B, Chisaka O, Jonas P, Schulte U, Fakler B, Klöcker N (2009) Functional proteomics identify cornichon proteins as auxiliary subunits of AMPA receptors. Science 323:1313-1319.

Seeburg PH (1993) The TINS/TiPS Lecture. The molecular biology of mammalian glutamate receptor channels. Trends Neurosci 16:359-365.

Shi Y, Lu W, Milstein AD, Nicoll RA (2009) The stoichiometry of AMPA receptors and TARPs varies by neuronal cell type. Neuron 62:633-640.

Shi Y, Suh YH, Milstein AD, Isozaki K, Schmid SM, Roche KW, Nicoll RA (2010) Functional comparison of the effects of TARPs and cornichons on AMPA receptor trafficking and gating. Proc Natl Acad Sci U S A 107:16315-16319.

Sobolevsky AI, Rosconi MP, Gouaux E (2009) X-ray structure, symmetry and mechanism of an AMPA-subtype glutamate receptor. Nature 462:745-756.

Soto D, Coombs ID, Renzi M, Zonouzi M, Farrant M, Cull-Candy SG (2009) Selective regulation of long-form calcium-permeable AMPA receptors by an atypical TARP, gamma-5. Nat Neurosci 12:277-285.

Tomita S, Chen L, Kawasaki Y, Petralia RS, Wenthold RJ, Nicoll RA, Bredt DS (2003) Functional studies and distribution define a family of transmembrane AMPA receptor regulatory proteins. J Cell Biol 161:805-816.

Tomita S, Adesnik H, Sekiguchi M, Zhang W, Wada K, Howe JR, Nicoll RA, Bredt DS (2005) Stargazin modulates AMPA receptor gating and trafficking by distinct domains. Nature 435:1052-1058.

Tomita S, Byrd RK, Rouach N, Bellone C, Venegas A, O’Brien JL, Kim KS, Olsen O, Nicoll RA, Bredt DS (2007) AMPA receptors and stargazin-like transmembrane AMPA receptor-regulatory proteins mediate hippocampal kainate neurotoxicity. Proc Natl Acad Sci U S A 104:18784-18788.

Vandenberghe W, Nicoll RA, Bredt DS (2005) Stargazin is an AMPA receptor auxiliary subunit. Proc Natl Acad Sci U S A 102:485-490.

Wang R, Walker CS, Brockie PJ, Francis MM, Mellem JE, Madsen DM, Maricq AV (2008) Evolutionary conserved role for TARPs in the gating of glutamate receptors and tuning of synaptic function. Neuron 59:9971008 .

Yamazaki M, Fukaya M, Hashimoto K, Yamasaki M, Tsujita M, Itakura M, Abe M, Natsume R, Takahashi M, Kano M, Sakimura K, Watanabe M (2010) TARPs gamma-2 and gamma-7 are essential for AMPA receptor expression in the cerebellum. Eur J Neurosci 31:2204-2220. 